\title{
Machine learning for metallurgy III: A neural network potential for Al-Mg-Si
}

\author{
Abhinav C. P. Jain $\odot,{ }^{1, *}$ Daniel Marchand,,${ }^{1, *}$ Albert Glensk $\odot,{ }^{1,2}$ M. Ceriotti, ${ }^{2}$ and W. A. Curtin ${ }^{1}$ \\ ${ }^{1}$ Institute of Mechanical Engineering, École Polytechnique Fédérale de Lausanne, CH-1015, Lausanne, Switzerland \\ ${ }^{2}$ Institute of Materials Science, École Polytechnique Fédérale de Lausanne, CH-1015, Lausanne, Switzerland
}

(Received 19 February 2021; accepted 19 April 2021; published 26 May 2021)

\begin{abstract}
High-strength metal alloys achieve their performance via careful control of the nucleation, growth, and kinetics of precipitation. Alloy mechanical properties are then controlled by atomic scale phenomena such as shearing of the precipitates by dislocations. Atomistic modeling to understand the operative mechanisms requires length and timescales far larger than those accessible by first-principles methods. Here, a family of Behler-Parinello neural network potentials (NNPs) for the Al-Mg-Si system is developed to enable quantitative studies of Al-6xxx alloys. The NNP is trained on metallurgically important quantities computed by first-principles density function theory (DFT) leading to high-fidelity predictions of intermetallic compounds, elastic constants, dilute solidsolution energetics, precipitate/matrix interfaces, Al stacking fault energies, antisite defect energies, and other quantities. The generalized stacking fault energy surfaces for the three prevalent $\beta^{\prime \prime}$ precipitate compositions in peak-aged Al-6xxx are then computed with the NNP, and are validated by DFT computations at key points. A preliminary examination of early stage clustering kinetics and energetics in Al-6xxx is then made, showing the formation of low-energy Mg-Si structures and the trapping of vacancies in these clusters. The NNP thus shows significant transferability across structures, making it a powerful approach for chemically accurate simulations of metallurgical phenomena in Al-Mg-Si alloys.
\end{abstract}

DOI: 10.1103/PhysRevMaterials.5.053805

\section{INTRODUCTION}

The plastic flow, fracture toughness, creep, fatigue, radiation resistance, and other mechanical properties of metals are related to the behavior of atomistic defects (dislocations, grain boundaries, interfaces, precipitates, crack tips, vacancies) and their motion and interactions. Understanding the detailed mechanisms, and ultimately designing alloys to control these mechanisms and achieve enhanced performance, is a major goal in metallurgy. Pursuit of that goal is greatly aided by atomic-scale simulations but the relevant length and timescales of the mechanisms and phenomena are often far too large to study by direct first-principles methods such as density-functional theory (DFT). Useful and predictive atomic simulations require chemically accurate but semiempirical classical interatomic potentials. The traditional approaches such as the embedded-atom method EAM or modified embedded-atom method MEAM can perform well against selected experimental or first-principles benchmarks but are often very inaccurate for other critical properties. Potentials for alloys generally have even more limited capabilities and accuracy due to restrictive assumptions of these frameworks. New approaches are thus essential to harness the power of atomistic computations for driving understanding and development of technologically valuable metal alloys.

Such a new approach is machine learning (ML) of the potential energy surface (PES) [1-9]. The construction of an ML potential involves (i) developing a database of energies

\footnotetext{
*A.C.P.J. and D.M. authors contributed equally to this work.
}

and forces of atomic structures, (ii) selecting a set of structural descriptors for the local atomic environments of the structures in the database [10-13], and (iii) applying a regression algorithm (e.g., neural network, kernel ridge regression) to optimize parameters in the ML method so as to best match the data set. The number of descriptors and parameters can be increased at will, and so an ML approach is parameter rich and can fit the configurations of the PES data set very well. Due the interpolative nature, ML potentials can fail to extrapolate accurately to regions of the PES outside the training database (training set). The atomic descriptors, the ML framework, and the scope of the training set all affect the resulting interatomic potential. Such factors also enter for traditional potentials, the difference being that the functional forms for traditional potentials are based on some underlying physics and have fewer parameters.

For broad applications of an ML interatomic potential (MLIP), selection of the training data set is essential [14-16]. Ideally, an exhaustive data set of relevant atomic environments with their energies and forces from electronic structure calculations is needed to improve transferability to new environments. Such relevant atomic environments are those needed to determine key physical properties of the material (see Fe [17] and W [9] within the GAP framework, for instance). Other approaches use more-automated methods of the selection of structures, such as random perturbations of bulk crystalline structures [18,19], and on-the-fly learning where an MLIP is used to evolve a system in time. The configurations for which the MLIP is deemed inaccurate are computed via DFT and used to update the MLIP [20-24]. These approaches limit costly DFT calculations to critical cases, but 
only within the framework of the configuration space sampled by molecular dynamics starting from a specified initial state. The physically informed neural-network (PINN) method is a hybrid approach that combines an analytical bond order potential (BOP) with a neural network that adjusts the BOP parametrization as a function of the specific environment [4]. The PINN method thus retains some expected physical bounds when extrapolated to new atomic environments.

For realistic metallurgical applications of MLIPs, it is essential to develop a database that explores metallurgically relevant structures associated with the many noncrystalline defects that are crucial to mechanical performance. This requires going well beyond the standard configurations such as the equilibrium structure, its elastic and vibrational response, single vacancies, a few high-symmetry surfaces, and occasionally liquid-state information. These structures are absolutely essential but are very far from sufficient for applications to realistic metallurgical problems. Several MLIPs have thus extended beyond basic properties. The GAP potentials for $\mathrm{Fe}$ [17] and $\mathrm{W}$ [9] included baseline data needed for describing dislocations structures and motion [25]. Kobayashi et al. [3] developed a neural network potential (NNP) for ternary Al-Mg-Si that included a wide range of intermetallics, solute-solute interactions, and interfaces, and showed good predictions for edge and screw dislocation structures, solute/dislocation interactions, and in situ precipitates; further development was shown by Imbalzano et al. [26]. Here, we will expand on the database used by Kobayashi et al. and employ an open-source code that will enable broad use of the NNPs developed here. Other methods are evolving toward modeling of realistic mechanical performance. The PINN method [4] showed application to an fcc edge dislocation, the active learning algorithm developed by Hodapp and Shapeev [6] examined the Peierls-type motion of a screw dislocation in $\mathrm{W}$, and Lopanitsyna et al. applied machine learning to compute accurate finite temperature properties of $\mathrm{Ni}$ [27]. Thus, progress is being made toward powerful MLIPs for metallurgy.

Here, we develop a new Al-Mg-Si neural network potential (NNP) for applications to Al-6xxx alloys, which are widely used in the automotive industry. The Behler-Parinello framework is used along with the open-source code N2P2 [10], with an extensive DFT training set of structures, energies, and forces. Relative to earlier work [3], in this work the training data is more extensive, the range of symmetry functions/descriptors is broader, the training and execution are accomplished within an open-source code that couples with the open-source molecular dynamics code LAMMMPS, and the resulting potential is used to provide new insights into several key issues in Al-6xxx alloys. Specifically, those preliminary applications to metallurgical problems are the shearing energies of $\beta^{\prime \prime}$ precipitates and the natural aging of $\mathrm{Al}-\mathrm{Mg}-\mathrm{Si}$ at room temperature, both of which are postvalidated via DFT results to further demonstrate the excellent transferability of the Al-Mg-Si NNP.

The remainder of this paper is structured as follows. In Sec. II, we summarize the methodology and details of the potential creation. In Sec. III we assess the overall NNP accuracy against many properties associated with the training set data. In Sec. IV, we present a study of the relevant GSFE shearing surfaces for three $\beta^{\prime \prime}$ precipitates, which is important for peakaged alloy strength. In Sec. V, we present preliminary results for natural aging in Al-6xxx alloys, which is important for alloy processing. Section VI contains concluding remarks.

\section{METHODOLOGY}

We first summarize the first-principles DFT methodology, the Behler and Parinello neural-network potential framework [10], and the training data sets used here.

\section{A. DFT methodology and database of structures}

The training of the MLIP is based on energies and forces calculated using first-principles density-functional theory (DFT) as implemented in QUANTUM ESPRESSO [28] (QE). The GGA-PBE [29] exchange-correlation functional is used with a cutoff energy of $544 \mathrm{eV}$ (40 Ry) and a $k$-point spacing 80/Å using the Monkhorst-Pack grid [30]. The MethfesselPaxton smearing scheme with a smearing of $0.6 \mathrm{eV}$ is used along with the solid-state pseudopotential (SSSP) library [31]. The AiiDA framework is used for systematic calculations of all structures in DFT, ensuring consistent convergence settings and facilitating data generation and management $[32,33]$. Details and references to the AiiDA scripts and work flows can be found in Ref. [7].

The DFT methodology is applied to a broad range of structures relevant for the modeling of precipitation, plasticity, and fracture in $\mathrm{Al}-\mathrm{Mg}-\mathrm{Si}$ alloys. Our main focus is on the dilute limit in the Al-rich region of the phase diagram, corresponding to the Al-6xxx alloys. Specifically, we incorporate selected structures from the $\mathrm{Al}-\mathrm{Mg}$-Si database of 10000 structures generated by Kobayashi et al. [3]. This database contains, among other structures,

(1) many Al-Mg-Si binary and ternary intermetallic phases, including three $\beta^{\prime \prime}$ phases relevant at peak aging;

(2) configurations for pure $\mathrm{Al}$ related to elasticity, vacancies, stacking fault energies;

(3) random fcc cells of Al-Mg-Si-vacancy over a range of solute concentrations;

(4) cells with random displacements of atoms away from the ideal fcc lattice sites.

All of the energies and forces for these structures have been recomputed using the DFT method here to be consistent with all additional data. We use a furthest-point-sampling scheme introduced by Imbalzano et al. [26] to select a subset of 4998 structures that show the largest variance among the 10000 structures.

We also include geometries generated by Giofre et al. [34] that include

(1) the most stable $\beta^{\prime}$ precipitate structures found in Al$\mathrm{Mg}-\mathrm{Si}$ alloys;

(2) two-dimensional (2D) and 3D precipitates structures embedded in an Al matrix, with and without elastic strain (small cell deformations);

(3) interface structures with different orientations between $\beta^{\prime \prime}$ precipitates and the $\mathrm{Al}$ matrix

plus a further 153 structures relevant to the calculation of various elastic constants and beyond the linear elastic limit using strains of up to $10 \%$. Finally, we added structures with 
large volumetric tension or compression for $\mathrm{Al}, \mathrm{Mg}, \mathrm{Si}, \beta^{\prime}$, and $\beta^{\prime \prime}$, specifically six structures with $\frac{a}{a_{0}}$ from $0.8-1.1$ for each composition. These structures are intended to increase the robustness of the MLIP to extreme conditions.

With an interest in modeling the evolution of precipitate formation, it is also necessary to have information on both antisite defect energies and vacancy formation energies inside the various precipitates. We thus study the formation energies of all possible antisites for the three metastable $\beta^{\prime \prime}$ phases. To further enhance the suitability for following precipitate evolution, we examined structures emerging from kinetic Monte Carlo simulations of early stage $\mathrm{Si}-\mathrm{Mg}$ clustering in $\mathrm{Al}$. Structures deemed most different from the training database were selected and computed via DFT, but found to be well predicted with no need to further refine the NNP. Thus, the initial comprehensive DFT data set was found sufficient for accurate study of precipitate evolution, and further validation is provided below.

\section{B. Neural network methodology}

Here we summarize the essential formulation of the neuralnetwork methodology introduced by Behler and Parrinello $[2,10]$. The total energy $E^{\text {structure }}$ of a particular structure is first represented as a sum over individual atomic energies $E_{i}^{\text {atom }}$,

$$
E^{\text {structure }}=\sum_{i} E_{i}^{\text {atom }}
$$

Each local atomic energy $E_{i}^{\text {atom }}$ is then calculated using a nested hierarchical function of weighted layers across a neural network. We use a neural-network architecture with two hidden layers and 24 nodes per layer. We have tested deeper networks with three layers that did not lead to improvements in the final errors with respect to DFT. The atomic energy is thus defined as

$$
\begin{aligned}
E_{i}^{\text {atom }}= & f_{3}\left\{b_{1}^{3}+\sum_{k=1}^{24} a_{k, 1}^{2,3} \cdot f_{k}^{2}\left[b_{k}^{2}+\sum_{j=1}^{24} a_{j, k}^{1,2}\right.\right. \\
& \left.\left.\cdot f_{j}^{1}\left(b_{j}^{1}+\sum_{i=1}^{64} a_{i, j}^{0,1} \cdot G_{i}\right)\right]\right\},
\end{aligned}
$$

where $a_{z, w}^{q, p}$ is the weight of node $z$ on layer $q$ to node $w$ on layer $p$, similarly $b_{z}^{q}$ is the bias of node $z$ on layer $q . f_{q}$ is an activation function; here we use the SOFTPLUS function $\ln (1+$ $\mathrm{e}^{x}$ ) for $f_{1}$ with $f_{2}$ and $f_{3}$ the identity functions. The $G_{i}$ are the descriptors for characterizing a local atomic environment, referred to as symmetry functions by Behler and Parinello.

We use two families of symmetry functions, a family of two-body radial symmetry functions

$$
G_{i}^{\text {radial }}=\sum_{j=1}^{N_{\text {atom }}} e^{-\eta\left(R_{i j}-R_{s}\right)^{2}} \cdot f_{c}\left(R_{i j}\right)
$$

and a family of three-body angular symmetry functions

$$
\begin{aligned}
G_{i}^{\text {angular }}= & 2^{1-\zeta} \sum_{j \neq i} \sum_{k \neq i, j}\left[\left(1+\lambda \cdot \cos \theta_{i j k}\right)^{\zeta} \cdot e^{-\eta\left(R_{i j}^{2}+R_{i k}^{2}+R_{j k}^{2}\right)}\right. \\
& \left.\cdot f_{c}\left(R_{i j}\right) \cdot f_{c}\left(R_{j k}\right) \cdot f_{c}\left(R_{j k}\right)\right]
\end{aligned}
$$

Here $\eta, \zeta$, and $\lambda$ are predefined so-called hyperparameters for a given symmetry function, $R_{i} j$ is the distance between atoms $i$ and $j$, and $f_{c}(r)=\tanh ^{3}\left(1-r / r_{c}\right)$ is a cutoff function where $r_{c}$ is a cutoff parameter for each symmetry function. A comprehensive summary of these descriptors can be found in Refs. [10-13]. The hyperparameters can be found in the file input.nn provided on the materials cloud [53]. Following Imbalzano et al. [26], we utilize 64 symmetry functions per element (192 symmetry functions overall), which we find to be a good balance between accuracy and computational cost. The symmetry functions used here are also provided in Appendix A 3.

The above methodology is executed within the N2P2 code $[35,36]$ to determine the weights of the neural network. The $\mathrm{N} 2 \mathrm{P} 2$ code randomly chooses $90 \%$ of the database structures for training of the weights and the remaining $10 \%$ of the structures for testing. We utilize the fading memory Kalman filter to update the NNP weights during training.

We assess the root mean square error (RMSE) for structures in the testing and training sets for both energies and forces separately,

$$
\begin{gathered}
R M S E(E)=\left[\frac{1}{n} \sum_{i}^{n}\left(E_{i}^{\mathrm{DFT}}-E_{i}^{\mathrm{NNP}}\right)^{2}\right]^{\frac{1}{2}} \\
\operatorname{RMSE}(F)=\left[\frac{1}{n} \sum_{i}^{n} \sum_{j}^{3 N_{i}} \frac{1}{3 N_{i}}\left(F_{i, j}^{\mathrm{DFT}}-F_{i, j}^{\mathrm{NNP}}\right)^{2}\right]^{\frac{1}{2}},
\end{gathered}
$$

where $E_{i}^{\mathrm{DFT}}$ and $E_{i}^{\mathrm{NNP}}$ are the respective DFT and NNP energies for a particular structure $i, F_{i, j}^{\mathrm{DFT}}$ and $F_{i, j}^{\mathrm{NNP}}$ are the respective DFT or NNP forces on atom $j$ of structure $i, n$ is the total number of structures, and $N_{i}$ the number of atoms of a particular structure with index $i$. Note that for each structure $i$ there is one energy, $E_{i}$, but $3 N_{i}$ forces, one in every spatial direction for every atom.

The objective (loss) function $\Gamma^{\text {loss }}$ that is minimized during the neural network optimization of the weights is given by

$$
\begin{aligned}
\Gamma^{\mathrm{loss}}= & \frac{1}{n} \sum_{i=1}^{n}\left[\left(E_{i}^{\mathrm{NNP}}-E_{i}^{\mathrm{DFT}}\right)^{2}\right. \\
& \left.+\frac{\alpha}{3 N_{i}} \sum_{j=1}^{3 N_{i}}\left(F_{i, j}^{\mathrm{NNP}}-F_{i, j}^{\mathrm{DFT}}\right)^{2}\right],
\end{aligned}
$$

where $\alpha$ controls the influence of forces on the loss function and is set to $8\left(\AA^{2}\right)$ in this work. The training was carried out for a fixed 500 epochs, which is found, via further testing, to be prior to the point at which the validation error begins to increase. With the optimized weights, we then utilize the $\mathrm{N} 2 \mathrm{P} 2$ interface in LAMMPS [37] for computing the energies and forces for determining the final physical properties of interest.

\section{ACCURACY OF THE NNP}

With the set of structures discussed in Sec. II, we created 20 different NNPs differing in the precise $90 \%$ training set and the initial random weights and biases. Limited studies show that variations among NNPs are due to the differences in training set rather than initial weights and biases. The 20 NNPs are not independent potentials since most of the training 

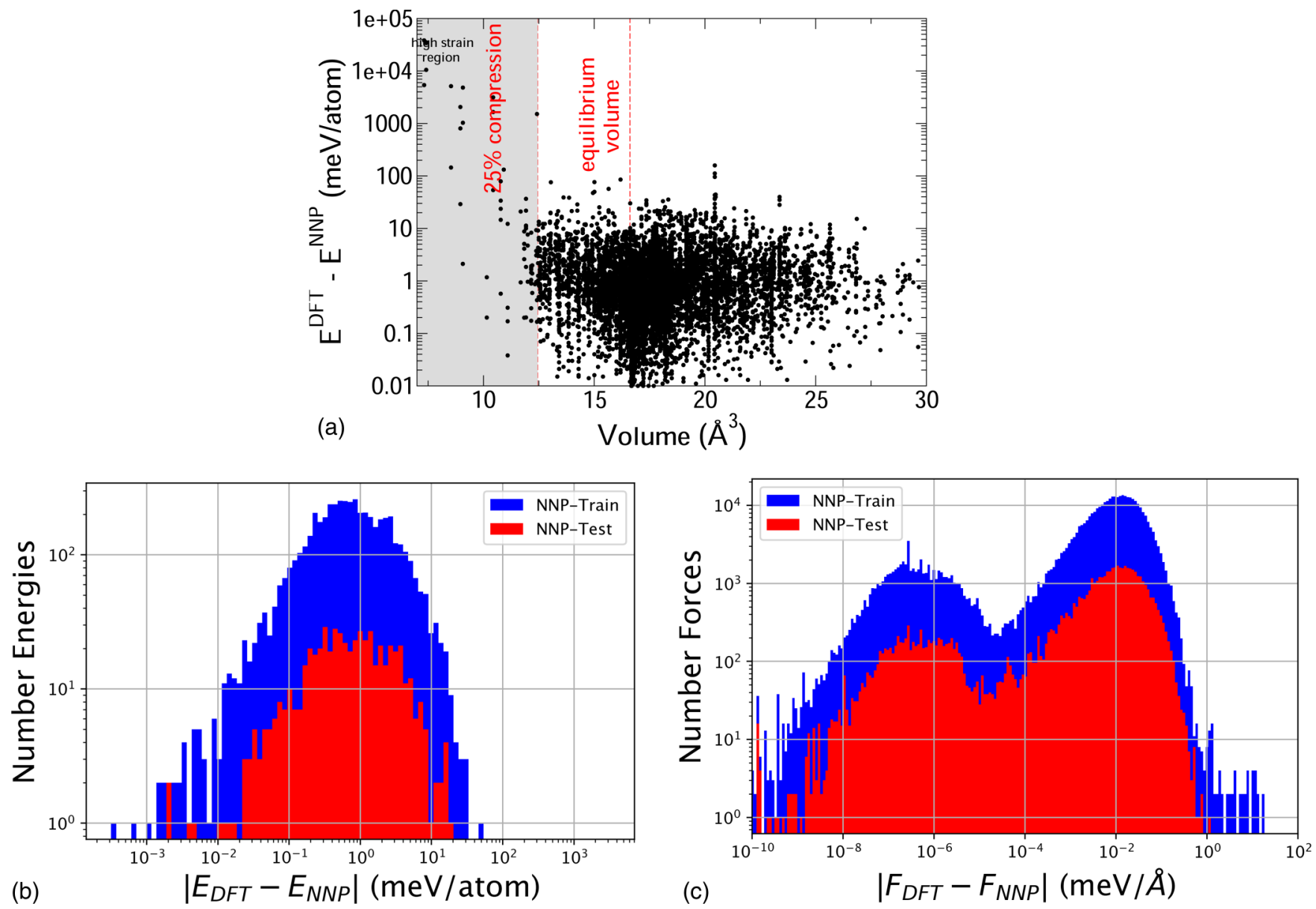

FIG. 1. (a) Energy difference $E^{\mathrm{DFT}}-E^{\mathrm{NNP}}$ for all test structures across all 20 NNPs as a function of the volume per atom. (b) Histogram of the difference between NNP and DFT energies for the training and test data of NNP16. (c) As in (b) but for the difference in forces.

structures are common to all of them, but the variations in overall error and in computed material properties is useful as a reflection of the reliability of the NNPs obtained using these training structures. From among the 20 NNPs, we have selected one particular final potential, labeled NNP16, for broader applications and usage. Over all 20 NNPs, there is an average RMSE for the energy of $2.75 \mathrm{meV} /$ atom for training and $204 \mathrm{meV} /$ atom for testing, while the training and testing RMSE for the forces are $27.1 \mathrm{meV} / \AA$ and $614 \mathrm{meV} / \AA$, respectively. At first glance the testing errors appear unacceptably large, indicating a poor average potential quality. However, the large testing errors are exclusively due to structures in the test set that have a very large compression of more than $25 \%$ as shown in Fig. 1(a). Specifically, all but two structures with an error above $100 \mathrm{meV} /$ atom have a separation of less than $1.8 \AA$ (as compared, for example, to the equilibrium distance in aluminum of $2.86 \AA$ ) and the other two structures are at fairly large expansion $(>20 \%)$. These errors then depend on whether the high-compression structures are in the training set or the test set. Only 4 of 20 potentials show testing errors of larger than $160 \mathrm{meV} /$ atom while 13 of 20 have quite lower RMSE of $4.46 \mathrm{meV} /$ atom. As discussed in Ref. [7], ML predictions at high compression are commonly highlighted as a failure of NNPs. At the same time, adding many such high-energy structures can reduce the quality of the resulting NNP in the domains of physical interest.
Serious failures at small atomic spacing can, fortunately, be circumvented by the ad hoc addition of a strongly repulsive potential for small atomic spacings. As discussed in Appendix A 1, we have added a cut-and-shifted repulsive Lennard-Jones potential to the NNP potential that is nonzero only at small atom separations. This prevents some problems that can be encountered when initial atomic configurations are created that have very close atomic spacings, as discussed later. The nature of the behavior at small spacings, with or without the added repulsive potential, is usually not operationally important because there are few metallurgical problems where such a high compression is accessed physically. Thus, while we have elaborated on these extreme limits of the NNP, the physical properties relevant for most materials modeling are not affected, as will be shown below.

Figures 1(b)-1(c) show the difference between NNP16 and the DFT data for the forces and energies of all structures in the training and test sets for NNP16. These results show that the vast majority of configurations, whether in the training or test sets, have force errors below $1 \mathrm{meV} / \mathrm{A}$ and energy errors below $20 \mathrm{meV} /$ atom, with most configurations having errors ten times smaller or more. This level of accuracy is sufficient for high accuracy in material properties derived from these configurations using NNP16, as discussed next. 


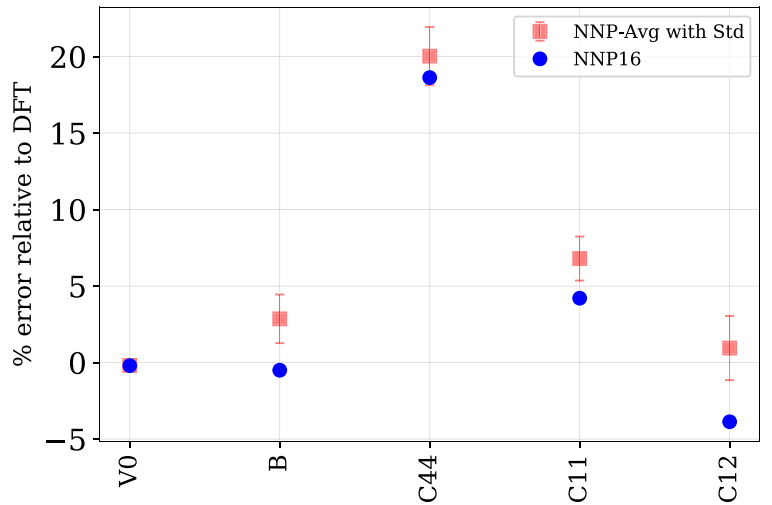

FIG. 2. Deviation of the average NNPs and of NNP16 from DFT (in \%) for volume and elastic constants of fcc Al. Red symbols and error bars: mean and standard deviation across 20 NNPs; blue symbols: NNP16.

\section{A. Alloy properties}

We now examine alloy properties that are derived from the structures in the training/test data set. We do not examine all relevant alloy properties; the level of agreement here for many properties is comparable to that obtained previously by Kobayashi et al., who used a different methodology. Results for pure $\mathrm{Al}$ are also similar to those presented recently in the development of an NNP for Al-Cu [7]. Instead, we focus on properties relevant to precipitate evolution that were not examined in detail previously.

Figure 2 shows the deviations of NNP16 with respect to $\mathrm{DFT}$, as a percentage, for selected properties in pure Al. In general, deviations of less than $5 \%$ are found for most quantities, with the exception of the elastic constants. The error of $20 \%$ for $C_{44}$ is common among MLIPs [7,38]. In general, deviations in elastic constants can be large because the elastic constants are the second derivatives of the energy, magnifying small energy differences between NNP and DFT. The stacking fault energy, important for dislocations in $\mathrm{Al}$, is, in contrast, very well predicted, as are the unstable stacking fault energy and vicinal surface energies that relate to fracture behavior at sharp crack tips [7].

The solid solution energies of individual solutes are important as the reference state for precipitation. The solid solution energy for a solute of type $X$ is defined as

$$
E_{X}^{S S}=E_{\mathrm{Al}_{M-1(X)}}-(M-1) E_{\mathrm{Al}_{M}} / M,
$$

where $X=\mathrm{Si}, \mathrm{Mg}$, vacancy $(\mathrm{V})$ with $E_{\mathrm{Al}_{M}}$ and $E_{\mathrm{Al}_{M-1(X)}}$ the total energies of supercells containing $M \mathrm{Al}$ atoms and $(M-1)$ $\mathrm{Al}$ atoms and one atom of $X=$, respectively. The energy $E_{\mathrm{Al}_{M-1(X)}}^{\text {tot }}$ is computed using a $3 \times 3 \times 3$ supercell of the cubic fcc cell (108 atoms) with the volume held fixed. The cell develops a small pressure due to the misfit volume of the solute but this contribution to the energy is less than $1 \mathrm{meV} /$ atom at this cell size. The $\beta^{\prime \prime}$ precipitate has a monoclinic structure with a 22 atom unit cell. This is included in the DFT data base for three different compositions $\mathrm{Mg}_{5} \mathrm{Si}_{6}, \mathrm{Mg}_{5} \mathrm{Al}_{2} \mathrm{Si}_{4}$, and $\mathrm{Mg}_{4} \mathrm{Al}_{3} \mathrm{Si}_{4}$ that are considered experimentally accessible. The precipitate formation energy, relative to the solid solution, for

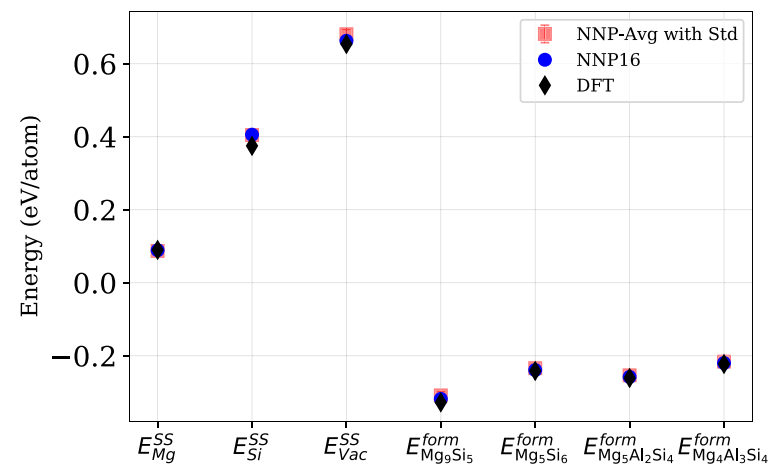

FIG. 3. Comparison of NNP16 and DFT results for Al solid solution energies of $\mathrm{Si}$ and $\mathrm{Mg}$, vacancy formation energy, and precipitate formation energies. The corresponding structures are included in the training set.

one formula unit of 11 atoms is

$$
E_{f . u .}^{\mathrm{form}}=\frac{1}{2} E_{\mathrm{Al}_{X} \mathrm{Mg}_{Y} S i_{Z}}^{\mathrm{tot}}-\sum_{X=\mathrm{Al}, \mathrm{Si}, \mathrm{Mg}} n_{X} E_{X}^{S S},
$$

where $E_{\mathrm{Al}_{X} \mathrm{Mg}_{Y} \mathrm{Si}_{Z}}^{\mathrm{tot}}$ is the total energy of a precipitate unit cell containing $X \mathrm{Al}$ atoms, $Y \mathrm{Mg}$ atoms, and $Z \mathrm{Si}$ atoms with all atomic positions fully relaxed. The solid solution energies and precipitate formation energies are summarized in Fig. 3. The $\mathrm{Mg}$ and vacancy solid solution energies are within $4 \%$ of the DFT value while that for Si shows a slightly larger deviation of $9 \%$ but still a very small absolute error of $0.031 \mathrm{eV}$. The overall agreement for precipitate formation energies is very good, deviating by at most $4 \%$.

The most stable precipitate in $\mathrm{Al}-\mathrm{Mg}-\mathrm{Si}$ is the $\beta^{\prime}$, with a hexagonal 28-atom unit cell containing two formula units of composition $\mathrm{Mg}_{9} \mathrm{Si}_{5}$ and one vacancy per formula unit. The DFT formation energy for the $\beta^{\prime}$ precipitate is $-0.328 \mathrm{eV} /$ atom, indeed below those for the $\beta^{\prime \prime}$ precipitates of $-0.261 \mathrm{eV}$ to $-0.222 \mathrm{eV}$. The $\beta^{\prime}$ structure was included in the original training set. The NNP prediction is also shown in Fig. 3, and deviates from the DFT reference by less than $4 \%$. The total energy per atom difference between $\beta^{\prime \prime} \mathrm{Mg}_{5} \mathrm{Si}_{6}$ and $\beta^{\prime} \mathrm{Mg}_{9} \mathrm{Si}_{5}$ is $0.086 \mathrm{eV} /$ atom as computed by the NNP, in good agreement with the value $0.079 \mathrm{eV} /$ atom computed by DFT. There is a small elastic mismatch between the $\beta^{\prime \prime}$ precipitates and the Al matrix. Figure 4 shows the difference between NNP and DFT computed elastic constants for the three $\beta^{\prime \prime}$ precipitates. Most of the results are within $10 \%$ of the DFT values, which we consider quite sufficient. The precise values of all the basic crystalline properties of the various $\beta^{\prime \prime}$ precipitates are provided in Appendix A 2.

Precipitate evolution involves nonstoichiometric compositions as the precipitates form. It is thus useful to examine the anti-site defect formation energies in the three $\beta^{\prime \prime}$ phases. Antisites are studied using 132-atom supercells of dimensions $a \times 3 b \times 2 c$ in terms of the precipitate primitive vectors [34]. The total energies $E_{\mathrm{Al}_{X} \mathrm{Mg}_{Y} \mathrm{Si}_{Z}}^{\mathrm{tot}}$ of the relaxed supercells containing $X \mathrm{Al}$ atoms, $Y \mathrm{Mg}$ atoms, and $Z \mathrm{Si}$ atoms are calculated with DFT to ensure accuracy with the primitive unit cells at similar but not identical $k$-point sampling densities. These supercells are first relaxed with the NNP to obtain the 


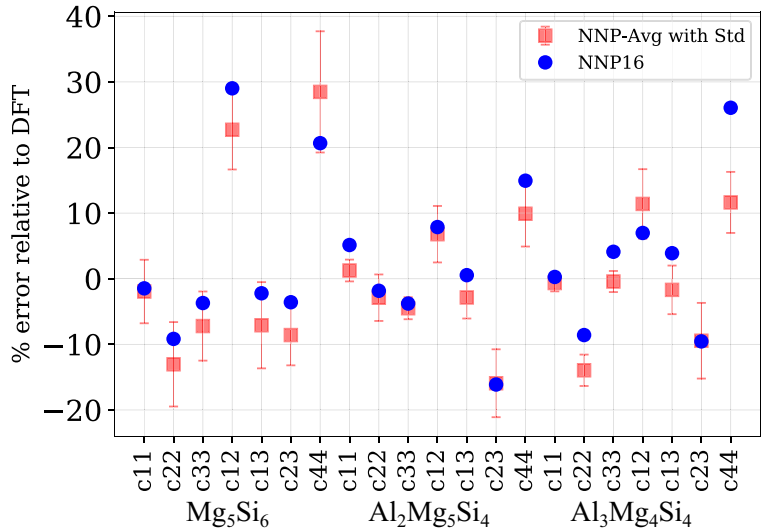

FIG. 4. Differences of NNP16 with respect to DFT for the elastic constants of the most relevant precipitates. The corresponding structures are included in the training set.

equilibrium cell volume and atom positions. Antisite defects are created by removing an atom $X$ at position $i$ in the supercell and replacing it with an atom $Y$, denoted as $X \rightarrow Y$, and relaxing with the NNP. The DFT calculations are carried out on the NNP relaxed geometries to obtain the total energies. The DFT cell is not relaxed so this energy is not the true antisite energy but nonetheless enables comparison to the NNP having exactly the same geometry. The total energy of the supercell is $E_{\mathrm{Al}_{X^{\prime}}}^{\mathrm{tot}} \mathrm{Mg}_{Y^{\prime}} \mathrm{Si}_{Z^{\prime}}$ where $X^{\prime}, Y^{\prime}$, and $Z^{\prime}$ are the numbers of $\mathrm{Al}, \mathrm{Mg}$, and $\mathrm{Si}$ atoms after the substitution.

The antisite formation energy is relative to the solid solution state, and so involves the energy of the $X$ atom placed into the solid solution and the $Y$ atom removed from the solid solution as

$$
\begin{aligned}
E_{\mathrm{Al}_{X^{\prime}} \mathrm{Mg}_{Y^{\prime}} S i_{Z^{\prime}}}^{\mathrm{form}}= & E_{\mathrm{Al}_{X^{\prime}} \mathrm{Mg}_{Y^{\prime}} \mathrm{Si}_{Z^{\prime}}-E_{\mathrm{Al}_{X} \mathrm{Mg}_{Y} \mathrm{Si}_{Z}}^{\mathrm{tot}}} \\
& -\left(X^{\prime}-X\right) E_{\mathrm{Al}}^{S S}-\left(Y^{\prime}-Y\right) E_{\mathrm{Mg}}^{S S} \\
& -\left(Z^{\prime}-Z\right) E_{\mathrm{Si}}^{S S} .
\end{aligned}
$$

Figures 5(a)-5(c) shows the formation energies of (unrelaxed) antisite defects inside the three $\beta^{\prime \prime}$ precipitates, without indication of the precise site position $i$. For $\mathrm{Mg}_{5} \mathrm{Si}_{6}$, nearly all antisite defects are positive and large $(>0.5 \mathrm{eV})$. The DFT results indicate that substitution of $\mathrm{Mg}$ at two of the Si sites is very slightly negative and here the NNP prediction deviates in predicting a positive value of $0.12 \mathrm{eV}$. These results suggest that the precipitate evolution favors higher $\mathrm{Mg}$ concentration, which would drive the nucleation of a $\beta^{\prime}$ precipitate. Both the $\mathrm{Al}_{2} \mathrm{Mg}_{5} \mathrm{Si}_{4}$ and $\mathrm{Al}_{3} \mathrm{Mg}_{4} \mathrm{Si}_{4}$ show similar trends where substituting $\mathrm{Al}$ with $\mathrm{Mg}$ lowers the energy, consistent with the $\mathrm{Mg}_{5} \mathrm{Si}_{6}$ having the lowest energy. The substitution of $\mathrm{Al}$ for $\mathrm{Si}$ is positive and small, with the NNP predicting slightly lower values than the DFT $(\sim 0.08 \mathrm{eV}$ vs. $\sim 0.16 \mathrm{eV})$. Different NNPs predict similar trends across the spectrum, especially for the most stable configurations, but none of the potentials predict negative energies when substituting $\mathrm{Si}$ with $\mathrm{Mg}$ in the $\mathrm{Mg}_{5} \mathrm{Si}_{6}$ precipitate.

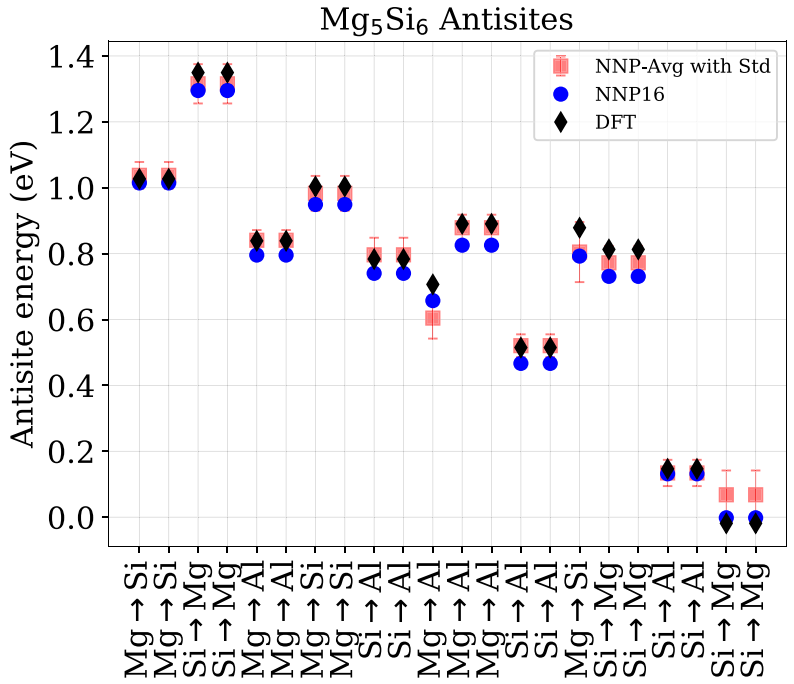

(a)

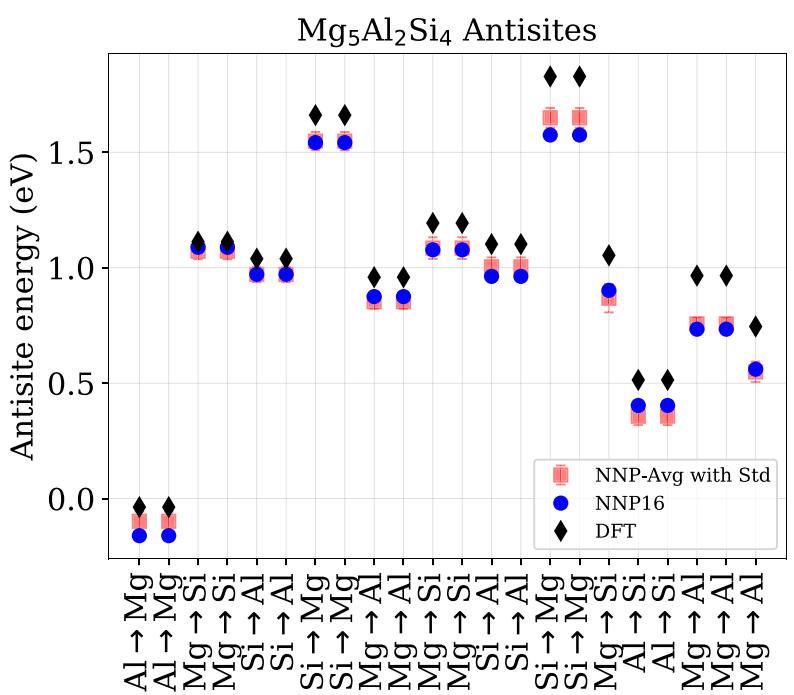

(b)

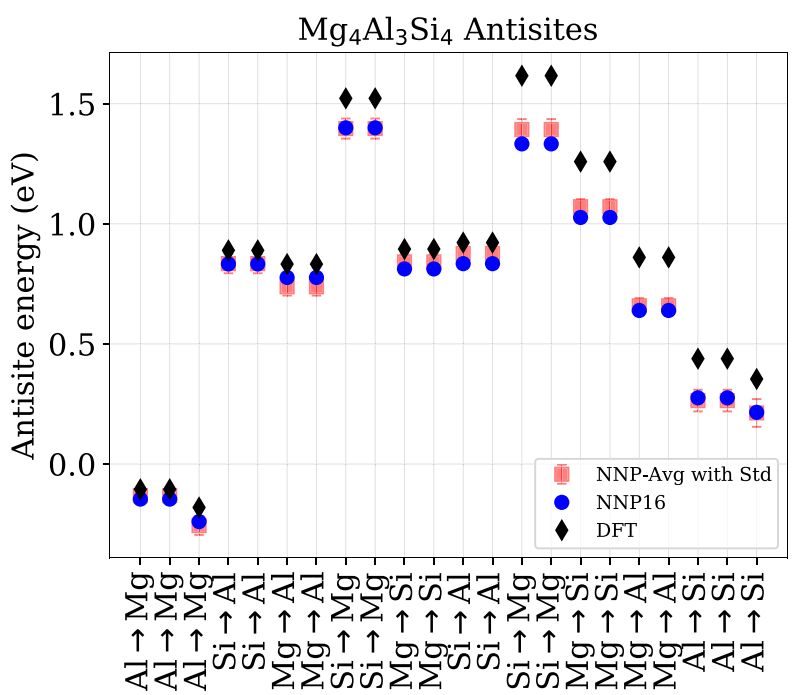

(c)

FIG. 5. Comparison of antisite energy computed using NNP16 and DFT. These structures are included in the training set. 


\section{APPLICATION: GENERALIZED STACKING FAULT ENERGIES OF $\beta^{\prime \prime}$ PRECIPITATES}

The mechanical properties of peak-aged $\mathrm{Al}-\mathrm{Mg}$-Si are controlled by dislocation motion through the field of $\beta^{\prime \prime}$ precipitates formed during aging. A recent study [39] suggests that precipitate shearing is the strength-limiting process. Thus the yield strength depends on the energetic cost of shearing the precipitates by dislocations impinging from the $\mathrm{Al}$ matrix. Here, we first identify the relevant crystallographic planes for shearing of in situ $\beta^{\prime \prime}$ precipitates; to our knowledge this analysis has not been done previously. We then use NNP16 to compute the shearing energies, known as the generalized stacking fault energy (GSFE) surface, for these surfaces. We compare the NNP results to DFT results at individual points corresponding to the six possible a (110)/2 dislocations in the Al matrix.

Slip in fcc metals occurs on the close-packed $\{111\}$ planes in the close-packed $\frac{1}{2}\langle 112\rangle$ directions. The precipitates are thus sheared along planes that are the closest to the matrix slip planes, since shearing along such planes creates the smallest residual Burgers vectors (and hence lowest residual energy) at the precipitate/matrix interface. We have computed the equivalencies between the parent Al-matrix $\{111\}$ planes and $\frac{1}{2}\langle 112\rangle$ directions and the daughter $\beta^{\prime \prime}$ precipitate using the crystallographic methodology described by Cayron [40] as implemented in the GenOVa program [41]. Not all $\{111\}_{A l}$ planes are equivalent in the $\beta^{\prime \prime}$ phase. We find that two groups of planes in $\beta^{\prime \prime}$, the $\{51 \overline{1}\}$ and $\{112\}$ as expressed in the $a, b, c$ lattice vectors for $\beta^{\prime \prime}$, are the best projections of the $\{111\}$ $\mathrm{Al}$ planes onto the $\beta^{\prime \prime}$ cell. The normal vectors for these two planes are misaligned from their $\mathrm{Al}$ equivalents by only 0.41 and 0.37 degrees, respectively.

Calculations of the GSFE surfaces are made using the tilted cell method as described in Ref. [42]. Input to the method is a structure whose plane of interest (here $\{51 \overline{1}\}$ or $\{112\}$ ) lies perpendicular to the $z$ axis while maintaining full 3D periodicity of the original structure. This geometric complication makes the method more challenging than the standard method that uses displacements of a rigid half-cell but is far more accurate and efficient. To construct a suitable cell, we first use the ase.build.surface method in the atomic simulation environment (ASE) package [43]. This tool generates a structure with the in-plane $a_{1}$ and $a_{2}$ vectors of the lattice cell on the plane of interest but the $a_{3}$ vector may not ensure periodicity. To create a periodic structure, we then choose an arbitrary atom and shift all positions so that this atom is centered at the origin. We then choose a new $a_{3}$ vector that points from the origin atom to an arbitrary atom of the same type, but at a higher $z$ coordinate, and wrap all positions with this periodicity and delete any duplicate (overlapping) atoms. To eliminate duplicates, we look for any atoms that lie on the same $z$ plane as the origin atom, set $a_{1}$ to be the position of this atom, wrap the positions, and delete the duplicates. The input and output structures are verified to maintain the same crystal structure using the spglib [44] library via an ASE wrapper. In the tilted cell method, it is the cell periodicity that is imposed, and the fault plane then appears at the cell boundary normal to the fault plane. We thus select an optimal cut plane by shifting the $z$ component of the atoms, while holding cell vectors and a1-a2 plane fixed, to maximize the $z$ distance of atoms on either side of the a1-a2 cut plane; i.e., we seek the most open plane as the likely lowest-energy plane. Our selection of cut plane was confirmed to be optimal by computing the entire GSFE surface, in the manner further detailed below, for all unique cut planes and confirming our selection had the lowest energy at all points.

The GSFE is obtained by shifting the $a_{3}$ vector by in-plane vectors $\mathbf{t}$ to $a_{3}+\mathbf{t}$ while keeping all atoms fixed. While the atoms are fixed in their absolute positions, interatomic distances above and below the cut plane will change as a function of $\mathbf{t}$ due to periodicity. This can result in atoms in the imposed initial structure that are extremely close together, causing numerical instabilities for both NNPs and, occasionally, DFT. Note that this problem is almost entirely one related to initial placement of atoms in very high-energy positions that would never arise naturally. The numerical issues associated with the NNP are largely avoided here by including the ad hoc repulsive LJ potential (see Appendix A 1) to the overall potential. To accelerate convergence, we ensure that any initial GSF configuration does not have excessive atomic overlap by increasing the $z$ component of $a_{3}$ by $c_{z}$, i.e., $a_{3}^{\prime}=a_{3}+\mathbf{t}+c_{z}$, to ensure a minimum distance of $2.0 \AA$ between all atoms. All the atoms in the cell and the $a_{3}$ vector are allowed to relax in the $z$ direction (normal to the fault plane). When using the additional repulsive potential, this step is not necessary. Finally, the $\frac{1}{2}\langle 112\rangle_{A l}$ Burgers vectors of Al are mapped into the $\beta^{\prime \prime}$ coordinates via the GenOVa program. However, when the $\beta^{\prime \prime}$ structure is converted from the conventional cell to the GSF cell, remapping of the Burgers vector is subtle. To achieve this, we create artificial atoms, one for each of the Burgers vectors of interest, in the conventional cell, create the GSF cell as above, and use the artificial atoms as markers for the Burgers vectors in the new cell.

Figure 6 shows atomistic images of the projected GSF geometries for the $\{112\}$ and $\{51 \overline{1}\}$ surfaces in $\mathrm{Mg}_{5} \mathrm{Si}_{6}$, with the fault plane and periodic units of material indicated for clarity. The geometries are complex, with many local atomic environments spanning the slip plane. The full computed GSFE surfaces for $\{112\}$ and $\{51 \overline{1}\}$ for the three compositions $\mathrm{Mg}_{5} \mathrm{Si}_{6}, \mathrm{Mg}_{4} \mathrm{Al}_{3} \mathrm{Si}_{4}$ and $\mathrm{Mg}_{5} \mathrm{Al}_{2} \mathrm{Si}_{4}$ are shown in Figs. 7 and 8. With the exception of the $\{112\}$ surface of $\mathrm{Mg}_{5} \mathrm{Si}_{6}$, all cases show a very smooth and continuous energy surface. With the use of the NNP plus the repulsive potential, we find a smooth GSFE. Using the NNP alone, even with attempts to minimize problems by adroit choice of the initial configuration, the \{112\} of $\mathrm{Mg}_{5} \mathrm{Si}_{6}$ shows regions where the NNP prediction collapses into a deep energy minimum associated with atoms coming extremely close together during the relaxation process. The additional repulsive potential has little or no effect for the large majority of the energy surface, but in $2 \%$ of cases we found that the system would always collapse upon removal of the repulsive term.

To quantitatively validate the GSFE predicted by the NNP, we have used similar computational cells in DFT to compute the GSFE at the slip of the six $\mathrm{Al} \mathrm{a}(110) / 2$ Burgers vectors. These points are indicated in Figs. 7 and 8. Note that these positions are not local minima, unlike the situation arising in simpler precipitates where cutting by matrix dislocations forms antiphase boundaries that are local minima. Figure 9 compares the NNP and DFT GSFE values for all shearing 


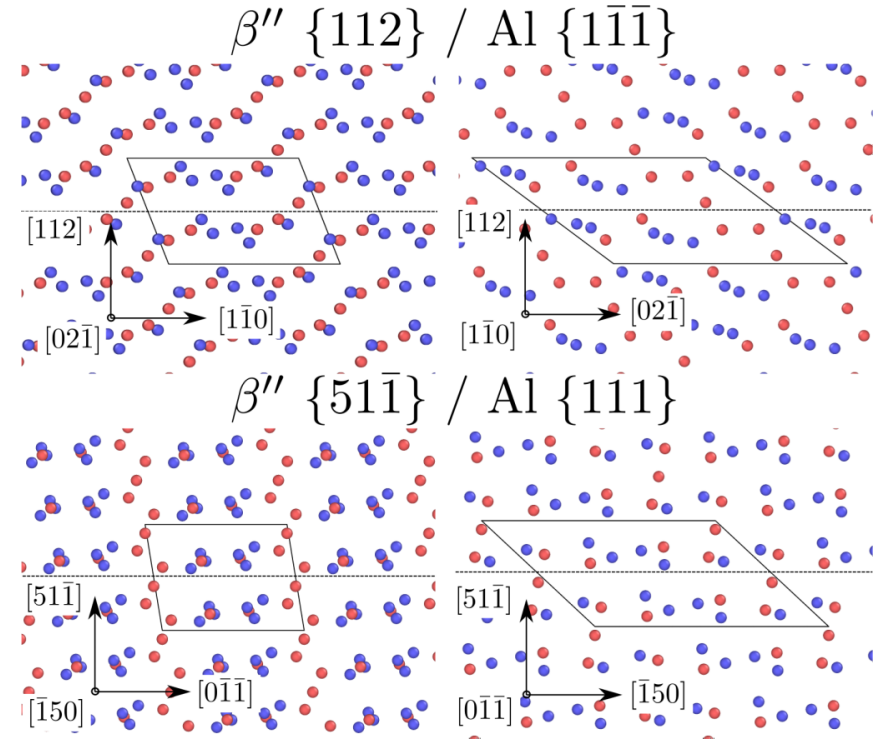

FIG. 6. Atomic view of the $\mathrm{Mg}_{5} \mathrm{Si}_{6} \beta^{\prime \prime}$ precipitate with normal planes $\{112\}$ and $\{51 \overline{1}\}$ appropriate for computing the generalized stacking fault energy surfaces relevant to precipitate shearing in an Al matrix. Dotted lines extend through the slip plane, and solid line highlight two periodic units of material above and below the slip plane, respectively.

planes in all three compositions for all six relevant Burgers vectors. The agreement is generally very good, recalling that no information directly related to these complex slip surfaces exists in the training data set. The NNP captures the fact that $\mathrm{Mg}_{5} \mathrm{Al}_{2} \mathrm{Si}_{4}$ has rather higher fault energies while those for $\mathrm{Mg}_{5} \mathrm{Si}_{6}$ and $\mathrm{M}_{4} \mathrm{Al}_{3} \mathrm{Si}_{4}$ are comparable. Quantitatively, the NNP is frequently within $100 \mathrm{~mJ} / \mathrm{m}^{2}$ of the DFT, although there are some differences of up to $150 \mathrm{~mJ} / \mathrm{m}^{2}$. The NNP is also typically larger than the DFT, which means that the NNP precipitates are more resistant to shearing than indicated by DFT.

Overall, while improvements to the NNP predictions would be desirable for fully quantitative results for shearing energies of $\beta^{\prime \prime}$, the performance of the NNP remains impressive. We are aware of few, if any, DFT computations of such complex GSFEs, much less any assessment of the performance of a traditional potential for such crucial but challenging structures. Results for $\mathrm{Al}-\mathrm{Cu}$ were presented recently, highlighting success of the NNP and notable failure of an established traditional potential [7]. We believe that the level of agreement here should enable insightful atomistic simulations of precipitate shearing, and hence alloy strengthening, that have heretofore been not feasible.

\section{PRELIMINARY APPLICATION: EARLY STAGES OF NATURAL AGING IN AL-6XXX}

After quenching from solutionizing temperatures to room temperature, Al-6xxx alloys undergo an undesirable natural aging, i.e., the formation of initial clusters of solutes made possible at room temperature by the presence of excess quenched-in vacancies. Here we present an initial study of early stage clustering using NNP16 in combination with offlattice kinetic Monte Carlo (KMC) simulations to demonstrate
TABLE I. Vacancy migration barriers for a single $\mathrm{Mg}$ or $\mathrm{Si}$ atom in the $\mathrm{Al}$ matrix.

\begin{tabular}{|c|c|c|c|}
\hline \multirow[b]{2}{*}{ Jump type } & \multicolumn{3}{|c|}{ Migration energy $[\mathrm{eV}]$} \\
\hline & DFT [47] & NNP16 & NNP-Avg / StdDev \\
\hline & 0.58 & 0.61 & $0.62 / 0.011$ \\
\hline & 0.68 & 0.74 & $0.75 / 0.016$ \\
\hline & 0.46 & 0.47 & $0.48 / 0.011$ \\
\hline & 0.52 & 0.52 & $0.53 / 0.011$ \\
\hline & 0.45 & 0.41 & $0.44 / 0.020$ \\
\hline
\end{tabular}

at a realistic alloy composition. These simulations were carried out within the framework of the I-PI code [45].

Since precipitation involves solute transport via vacancymediated solute diffusion, achieving quantitative timescales using the NNP requires accurate migration barriers. No information regarding migration barriers was included in the NNP training set, however. Here, we thus present the basic migration barriers for $\mathrm{Al}, \mathrm{Mg}$, and $\mathrm{Si}$ that govern the frequencies that enter the five-frequency model for solute diffusion [46] in the matrix as further validation of the transferability of the NNP. Specifically, we have examined five different vacancy transitions: $\mathrm{Al}-V$ exchange in $\mathrm{Al}$ (related to $\mathrm{Al}$ self-diffusion), $\mathrm{Al}-V$ exchange adjacent to a $\mathrm{Mg}$ atom, Al- $V$ exchange adjacent to a $\mathrm{Si}$ atom, $\mathrm{Mg}-V$ exchange in the $\mathrm{Al}$ matrix, and $\mathrm{Si}-V$ exchange in the Al matrix. Table I compares the DFT and NNP16 migration barriers for these five transitions. The agreement is quite good, within a few $\mathrm{meV}$ in all cases, with the largest deviation of only $5 \mathrm{meV}$ for the Al- $V$ exchange adjacent to a $\mathrm{Mg}$ atom. Results for all $20 \mathrm{NNPs}$ are similar, with variations of only about $+/-1 \mathrm{meV}$. The NNP potential should thus provide quite accurate diffusion coefficients for $\mathrm{Al}, \mathrm{Mg}$, and $\mathrm{Si}$ in dilute $\mathrm{Al}$, giving accurate long-range solute transport through the $\mathrm{Al}$ matrix.

Turning to the precipitate evolution, the KMC simulations are topologically on lattice but with full atomistic relaxation of every configuration studied. Thus, every atom can be uniquely associated with an underlying fcc lattice site but the actual atom positions deviated from the ideal lattice due to the atomic size mismatch (misfit strains). To date, we find no configurations where the topology of the system is altered. The vacancy can then also be associated with a specific lattice site for bookkeeping purposes. KMC then requires the migration barriers for all 12 possible transitions of a vacancy from its current site to the surrounding fcc neighbor sites at each time step. The vacancy starts at a random lattice site in the fcc supercell containing $N-1$ atoms. The vacancy is 

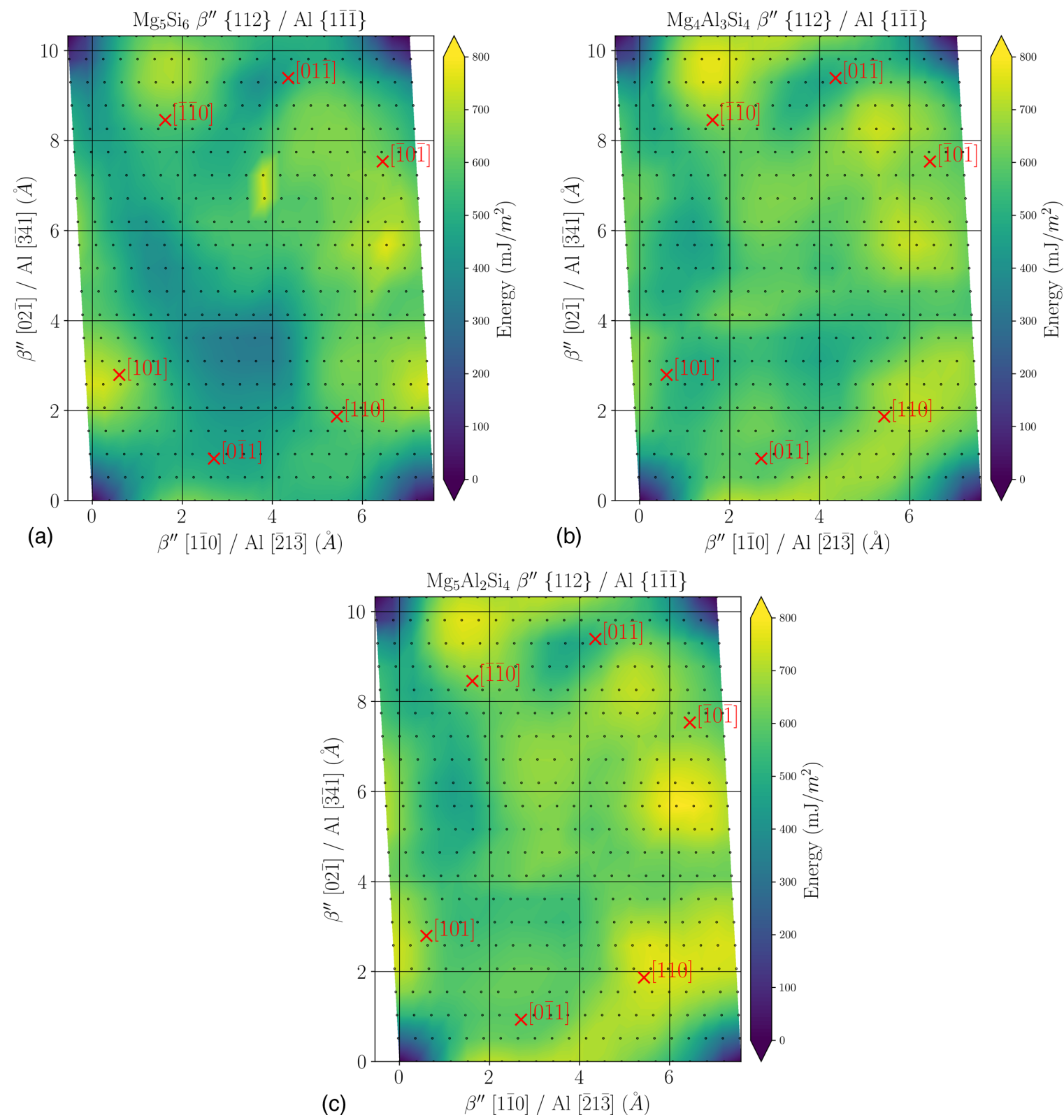

FIG. 7. GSFE for the $\{112\}$ plane of $\beta^{\prime \prime}$ for $\mathrm{Mg}_{5} \mathrm{Si}_{6}, \mathrm{Mg}_{4} \mathrm{Al}_{3} \mathrm{Si}_{4}$, and $\mathrm{Mg}_{5} \mathrm{Al}_{2} \mathrm{Si}_{4}$ obtained using the NNP plus the repulsive potential. Without the repulsive potential, a few points on the $\mathrm{Mg}_{5} \mathrm{Si}_{6}$ surface would have an unphysical collapse into a deep energy minimum; none of these points corresponding to any aluminum Burger vector.

then exchanged with each of its 12 neighbors, and the entire atomistic system relaxed to a minimum energy state for each case; this provides the initial and final state energies for each possible transition. It is computationally intensive to compute the migration barriers for each specific chemical environment during the natural aging. Thus, while the NNP captures the dilute migration barriers very well (Table I), we make a simplifying approximation to avoid direct computation of specific migration barriers. Specifically, we use linear interpolation to approximate the migration barriers of all solute-vacancy exchanges as

$$
E_{i-f}^{M}=E_{A l}^{M}+\left(E_{f}-E_{i}\right) / 2,
$$

where $E_{i}$ and $E_{f}$ are the fully relaxed NNP energies of the initial and final states (before and after migration) and $E_{A l}^{M}=$
$0.58 \mathrm{eV}$ is the vacancy migration barrier in $\mathrm{Al}$ as computed from DFT. The linear approximation ensures that detailed balance is satisfied and that the configurational energy landscape is sampled correctly, but it does not capture the true precise timescale of clustering. The differences in migration barrier in the dilute limit are not entirely negligible, with the controlling barrier for Si diffusion lower by $-0.06 \mathrm{eV}$ and that for $\mathrm{Mg}$ higher by $0.1 \mathrm{eV}$, but are small enough for the present preliminary application.

The KMC simulations are standard. We construct a catalog of rates $w_{i-f}$ for the vacancy to jump from the initial configuration $i$ to the 12 nearest neighbors $f=1,2, . .12$ with $w_{i-f}=v \exp ^{-E_{i-f}^{M} / k_{\mathrm{B}} T}$, where $v$ is an attempt frequency set to $16.6 \mathrm{THz}$ [48] for all transitions. One transition is randomly chosen based on the relative probability of the 
(a)

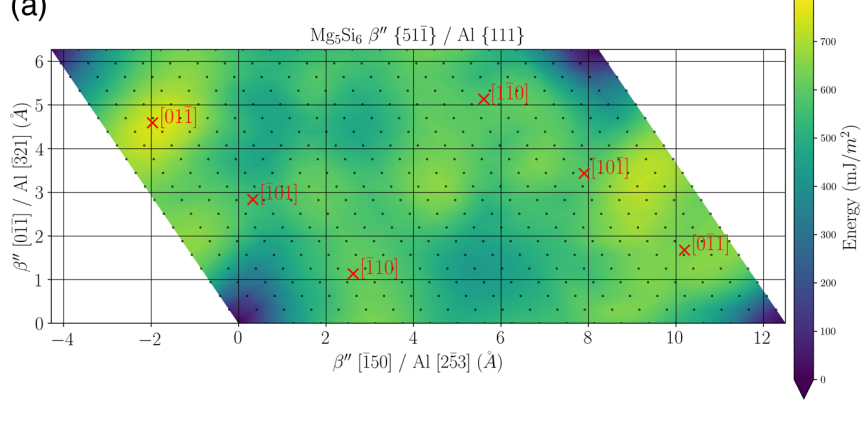

(b)

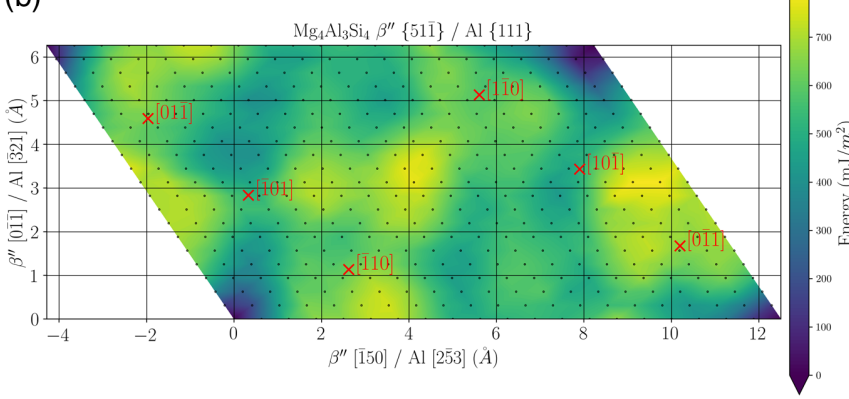

(c)

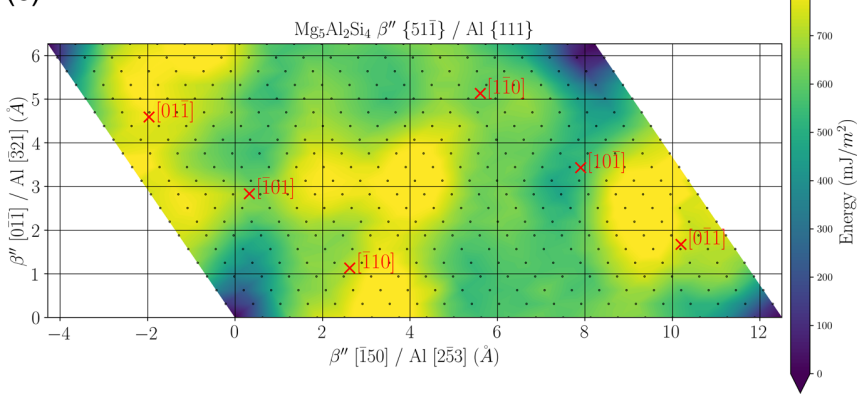

FIG. 8. GSFE for the $\{51 \overline{1}\}$ plane of $\beta^{\prime \prime}$ for $\mathrm{Mg}_{5} \mathrm{Si}_{6}, \mathrm{Mg}_{4} \mathrm{Al}_{3} \mathrm{Si}_{4}$, and $\mathrm{Mg}_{5} \mathrm{Al}_{2} \mathrm{Si}_{4}$.

different rates. The time step for the KMC move is then $t=-\log u / \sum_{f} w_{i-f}$, where $u$ is a random number in the range $(0,1]$. The process is repeated for each new vacancy position.

Simulations of natural aging $(T=300 \mathrm{~K})$ are carried out in 1000 and 1728 atom supercells, each containing one vacancy and an initial random distribution of $\mathrm{Mg}$ and $\mathrm{Si}$ solutes at the near-commercial concentration of $\mathrm{Mg} 1 \% \mathrm{Si} 0.6 \%$. The vacancy concentration $\left(10^{-3}\right.$ in the 1000 atom cell) is far higher than expected after quenching in real alloys $\left(10^{-5}-10^{-6}\right)$. This difference correspondingly accelerates the overall apparent timescale of aging by 2-3 orders of magnitude. The times in the $\mathrm{KMC}$ are thus scaled by a factor of $10^{3}$ (vacancy concentration $10^{-6}$ ) to make more-reasonable contact with timescales pertinent in real alloys.

Figure 10 shows the evolution of the 1000-atom system energy with time for three different simulations along with the root mean square displacement of the vacancy (exiting and reentering the periodic cell mimicking longer-range motion). At early times, the vacancy migrates in the bulk and pairs with a $\mathrm{Si}$ atom due the attractive binding energy. The $\mathrm{Si}-V$

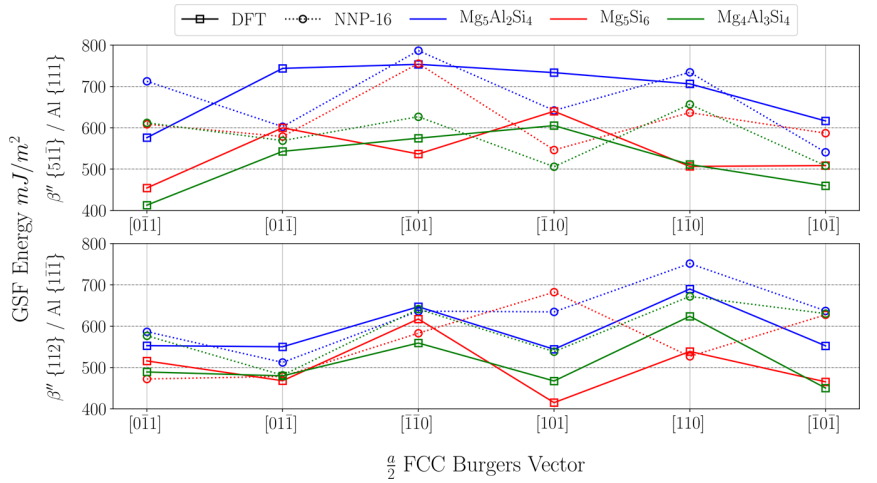

FIG. 9. Burgers vector vs GSF energy using NNP-16 and DFT for $\mathrm{Mg}_{5} \mathrm{Si}_{6}, \mathrm{Mg}_{5} \mathrm{AlSi}_{4}$, and $\mathrm{Mg}_{4} \mathrm{Al}_{3} \mathrm{Si}_{4}$ in both the $\{51 \overline{1}\}$ and $\{112\}$ configurations. The NNP shows excellent ability to predict general trends, e.g., that [011] in $\mathrm{Mg}_{5} \mathrm{Al}_{2} \mathrm{Si}_{4}$ is one of the highest-energy points corresponding to an Aluminum fcc Burgers vector and [0 $\overline{1} 1]$ with $\mathrm{Mg}_{5} \mathrm{Si}_{6}$ has one of the lowest-energy points. These energies do not include the $\mathrm{LJ}$ term, using the $\mathrm{LJ}$ term is largely the same, with a few points deviating by $10 \mathrm{~mJ} / \mathrm{m}^{2}$.

pair migrates, eventually encountering $\mathrm{Mg}$ or another $\mathrm{Si}$ atom, which leads to triplet formation and cluster growth. These small clusters are unstable and go through cycles of formation and dissolution, as indicated by the energy fluctuations in the figure. More-stable, lower-energy clusters form due to aggregation of at least three $\mathrm{Si}$ and three $\mathrm{Mg}$ atoms, with the plateaus in vacancy RMS displacement showing that the vacancy remains within or around these clusters. Figure 11 shows a typical cluster at one instant of time consisting of five $\mathrm{Mg}$ atoms, five $\mathrm{Si}$ atoms, and the vacancy. These typical more-stable clusters have energies of $-1 \mathrm{eV}$ to $-1.3 \mathrm{eV}$ relative to the solid solution, with the vacancy as part of the cluster. They form over a time of approximately $5 \mathrm{~min}$ and with vacancy diffusion over distances of $\sim 1000 \AA$, both in good agreement with experiments [49]. Cluster evolution then slows considerably due to a combination of vacancy trapping (see below) and depletion of $\mathrm{Si}$ in the matrix. However, these more-stable clusters can still dissolve partially or fully, as seen at the later times of two of the three simulations shown, which will be examined semiquantitatively below. Multiple simulations carried out with different starting configurations lead to similar geometries, energies, and timescales. A full characterization of typical clusters and their role in trapping vacancies will be presented in forthcoming work.

Simulations on the 1728 atom cell reduce size effects due to depletion of solutes. Figure 12 shows one example of the energy versus time and vacancy RMS displacement. After the early stages of few-solute cluster formation and dissolution, the nucleation of low-energy clusters occurs on a similar timescale as in the smaller system. However, now the presence of more $\mathrm{Si}$ atoms enables the formation of larger and more-stable precipitates with typical energies in the range of $-1.2 \mathrm{eV}$ to $-1.9 \mathrm{eV}$, including the vacancy in the cluster. These larger clusters persist to much longer times (hours), with the vacancy also remaining trapped for much longer times. The vacancy periodically escapes the trap, indicated by the spikes in both displacement and energy curves, but 

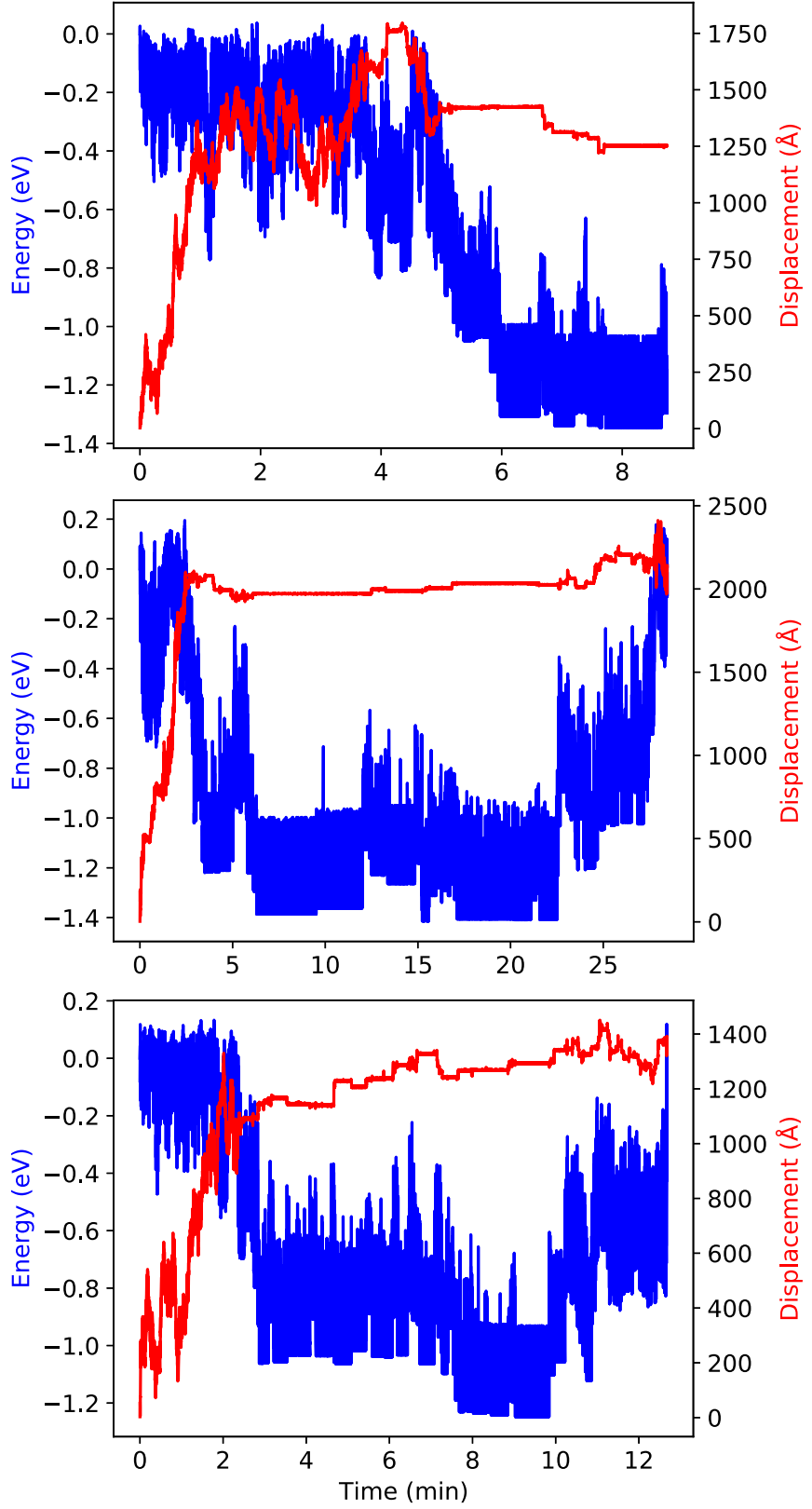

FIG. 10. Energy and vacancy displacement vs simulation time for three different KMC simulations carried out with the NNP using a 1000 atom supercell containing $10 \mathrm{Mg}$ atoms and $6 \mathrm{Si}$ atoms. The simulations were carried out for $5 \times 10^{6}$ steps.

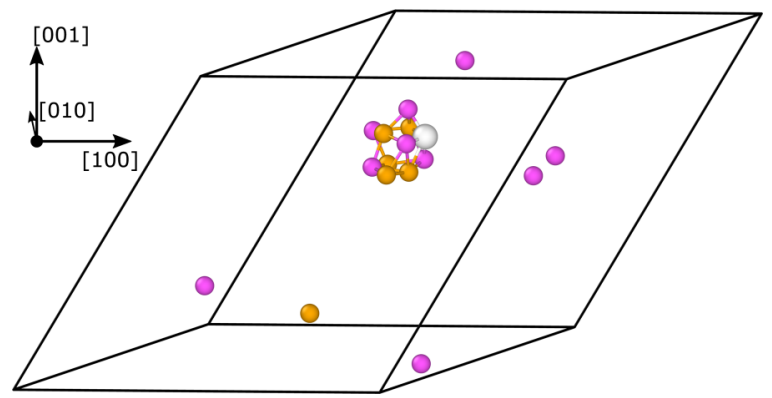

FIG. 11. Geometric illustration of a low-energy $\mathrm{Mg}$-Si cluster formed during the $\mathrm{KMC}$ simulation with $10 \mathrm{Mg}$ and $6 \mathrm{Si}$ atoms in a 1000 atom cell.

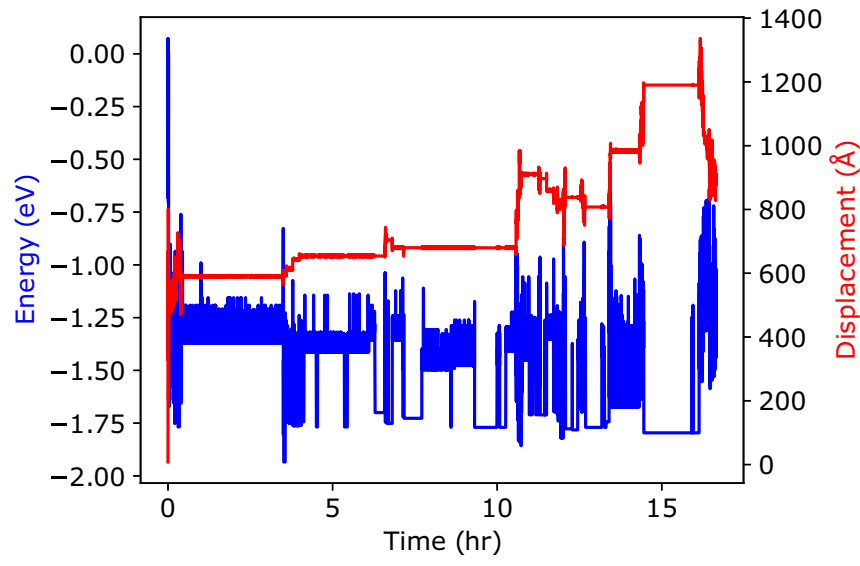

FIG. 12. Energy and vacancy displacement vs simulation time for the KMC simulations carried out with the NNP using a 1728 atoms supercell containing $17 \mathrm{Mg}$ atoms and $10 \mathrm{Si}$ atoms. The simulation was carried out for $1.5 \times 10^{7}$ steps.

becomes trapped again, and the clusters show no indications of significant dissolution over the timescales simulated. Figure 13 shows a typical cluster at $11 \mathrm{~h}$ of simulation time, where the vacancy is trapped within a cluster of eight $\mathrm{Mg}$ and seven $\mathrm{Si}$ atoms. The remaining solutes in solution are more numerous, i.e., not near depletion, and yet further growth is not observed over the simulation time.

To further validate the accuracy of the NNP for these KMC simulations and to quantify vacancy trapping energies, periodic cells of 108 atoms containing a small KMC cluster (five $\mathrm{Mg}$, five $\mathrm{Si}, 1 \mathrm{~V}$ ) and a large $\mathrm{KMC}$ cluster (eight $\mathrm{Mg}$, seven $\mathrm{Si}, 1 V$ ) were created and fully relaxed to the equilibrium cell volume and zero stress using both the NNP and full DFT. Although such calculations are not a true representation of the clusters embedded within the Al bulk, they provide comparable energy estimates and serve as a performance benchmark for the NNP. Table II shows the NNP16 and DFT cluster formation energies with the vacancy and with the vacancy replaced by an $\mathrm{Al}$ atom, for both clusters. The very good agreement between DFT and NNP16 demonstrates the chemical accuracy of the NNP in all cases. The cluster-vacancy binding energy is simply the difference between the cluster formation energies with the vacancy and with the vacancy replaced by an $\mathrm{Al}$ atom with the vacancy in the bulk matrix. The

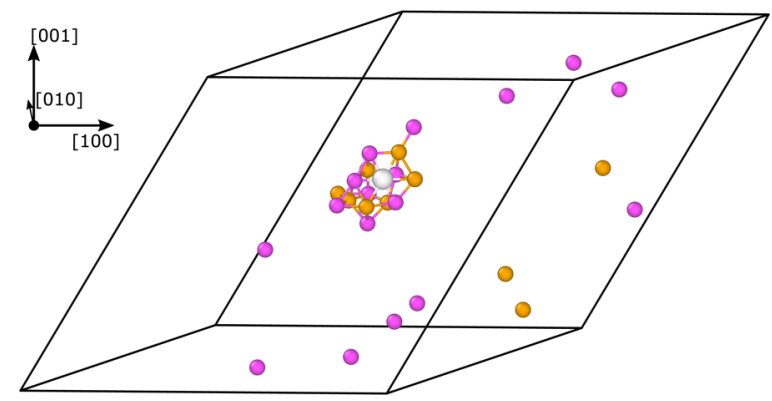

FIG. 13. Geometric illustration of a typical low-energy Mg-Si cluster formed during the KMC simulation with $17 \mathrm{Mg}$ and $10 \mathrm{Si}$ atoms in a 1728 atom cell. 
TABLE II. (a) The formation energies $\left(E_{\text {Cluster }}^{f}\right)$ of the clusters obtained from KMC simulations, computed from NNP16 and DFT using 108 atom supercells. The binding energy is the difference between the formation energies of the cluster with and without the vacancy. (b) The free energies of solid solution (SS), and the clustered geometry with remaining solid solution for 1000 atoms and 1728 atoms supercells with commercial alloy composition.

\begin{tabular}{|c|c|c|c|}
\hline & NNP16 & DFT & $\mathrm{NNP}-\mathrm{DFT}$ \\
\hline \multicolumn{4}{|c|}{ (a) Cluster formation energies $(\mathrm{eV})$} \\
\hline$E_{\mathrm{Mg}_{5} \mathrm{Si}_{5} V}^{f}$ & -0.984 & -1.090 & 0.106 \\
\hline$E_{\mathrm{Mg}_{5} \mathrm{Si}_{5}}^{f}$ & -0.678 & -0.636 & -0.041 \\
\hline Vacancy binding energy & -0.306 & -0.454 & 0.147 \\
\hline$E_{\mathrm{Mg}_{0} \mathrm{Si}_{7} V}^{f}$ & -1.478 & -1.654 & -0.011 \\
\hline$E_{\mathrm{Mg}_{8} \mathrm{Si}_{7}}^{f}$ & -0.925 & -0.914 & 0.178 \\
\hline \multirow[t]{2}{*}{ Vacancy binding energy } & -0.553 & -0.742 & 0.189 \\
\hline & E & $-T S$ & $F$ \\
\hline \multicolumn{4}{|c|}{ (b) Free energies at $T=300 \mathrm{~K}(\mathrm{eV})$} \\
\hline $\mathrm{Al}_{984} \mathrm{Mg}_{10} \mathrm{Si}_{6}(\mathrm{SS})$ & 0 & -2.293 & -2.293 \\
\hline $\mathrm{Al}_{4} \mathrm{Mg}_{5} \mathrm{Si}_{5}$ (Cluster $\left.+\mathrm{SS}\right)$ & -0.678 & -1.267 & -1.945 \\
\hline $\mathrm{Al}_{1701} \mathrm{Mg}_{17} \mathrm{Si}_{10}(\mathrm{SS})$ & 0 & -3.914 & -3.941 \\
\hline $\mathrm{Al}_{5} \mathrm{Mg}_{8} \mathrm{Si}_{7}$ (Cluster $\left.+\mathrm{SS}\right)$ & -0.925 & -2.407 & -3.332 \\
\hline
\end{tabular}

NNP cluster-vacancy binding energy is $-0.306 \mathrm{eV}$ (NNP16) for the small cluster and $-0.553 \mathrm{eV}$ for the large cluster, both slight underestimates relative to DFT. The vacancy binding energy of $-0.306 \mathrm{eV}$ for the ten solute atoms cluster is similar to the binding energy found for trapping of vacancies by individual Sn atoms [46] in Al-6xxx with the addition of 90 appm of Sn, which was found to retard natural aging by several weeks. Thus, the trapping of vacancies in Al-6xxx by these small solute clusters significantly limits further solute transport, slowing all kinetic processes at this stage of cluster development. The vacancy binding energy of $-0.553 \mathrm{eV}$ for the larger 15 solute atom cluster prevents vacancy escape on much longer timescales, slowing kinetics even more significantly, and potentially limits further precipitate evolution even at artificial aging temperatures (443 K).

To further assess stability of the clusters observed in the simulations, we can estimate the Helmholtz free energies of these systems relative to the random solid solution. The solid solution free energy is essentially due to entropy and so given by

$$
F_{s s}(T)=-k_{\mathrm{B}} T \ln \left(\frac{N !}{N_{A l} ! N_{M g} ! N_{S i} !}\right) .
$$

The free energy in the clustered state is estimated by a combination of the cluster energy, the cluster entropy, and the remaining solid solution entropy. We consider a generic compact cluster consisting of a total of $N_{c}$ atoms, composed of $N_{c, A l}, N_{c, M g}$, and $N_{c, S i}$ specific solutes. The total free energy is then estimated as

$$
F_{\text {clustered }}(T)=E_{\text {cluster }}-k_{\mathrm{B}} T\left[\ln \left(\frac{N_{c} !}{N_{c, A l} ! N_{c, M g} ! N_{c, S i} !}\right)+\ln \left(\frac{\left(N-N_{c}\right) !}{\left(N_{A l}-N_{c, A l}\right) !\left(N_{M g}-N_{c, M g}\right) !\left(N_{S i}-N_{c, S i}\right) !}\right)\right] .
$$

Applying these results to the 1000 atom cell with $N_{A l}=984$, $N_{M g}=10, N_{S i}=6$, at $T=300 \mathrm{~K}$, we compute $F_{s s}(T)=$ $-2.293 \mathrm{eV}$ for the solid solution as shown in Table II. A typical observed cluster has $N_{c, M g}=5, N_{c, S i}=5$, and $N_{c, A l}=4$ $\left(N_{c}=14\right)$ and we use the energy $E_{\text {cluster }}=-0.678 \mathrm{eV}$ found for one cluster without the vacancy as typical. The free energy of the clustered state is then estimated to be $F_{\text {clustered }}=$ $-1.945 \mathrm{eV}$. The free energies of the solid solution and the observed clusters are roughly comparable, and become very similar when the vacancy binding to the cluster (entropy neglected) is considered. This indicates rough equilibrium between the two states and hence ongoing dissolution and reformation of the clusters, as suggested by the KMC simulations here. Considering the 1728 atom cell, we have $N_{A l}=1701$, $N_{M g}=17, N_{S i}=10$ and, at $T=300 \mathrm{~K}, F_{S s}(T)=-3.914 \mathrm{eV}$ (Table II). For a typical larger cluster (13), we take $N_{c, M g}=8$, $N_{c, S i}=7$ and $N_{c, A l}=5$ (so $N_{c}=20$ ) and energy $E_{\text {cluster }}=$ -0.925 , leading to the free energy of the clustered system as $-3.332 \mathrm{eV}$. This is again roughly comparable, and nearly equivalent if the vacancy binding is included. Hence, even the larger clusters might be susceptible to dissolution but the vacancy trapping slows the kinetics considerably so that no such dissolution is observed over the KMC timescales studied so far. The above results are only preliminary estimates, and so should not be taken as definitive measures of the relative system stability.
Overall, the KMC simulations find thermodynamically low-energy, long-lived solute clusters of 10-15 solute atoms, with sufficiently low formation energies to roughly balance the entropy costs in the simulation cell at room temperature. The timescales and diffusion lengths needed for the formation of such clusters are comparable to experimental observations. A major observation is, furthermore, the strong trapping of vacancies in these clusters, which slows further evolution. This is fully consistent with experimental deductions of solute clusters as so-called vacancy prisons in $\mathrm{Al}-\mathrm{Mg}-\mathrm{Si}$ [50].

\section{CONCLUSION}

We have developed, validated, and applied a family of near-DFT-accurate Behler-Parinello-type neural network potentials (NNPs) for the Al-Mg-Si system. A key aspect in the development is the building of a comprehensive data set of metallurgically relevant structures with energies and forces computed from DFT. These NNPs are demonstrably accurate in predicting notable alloy properties such as lattice constants, elastic constants, surface and stacking fault energies, dislocation structures (not studied here), precipitate formation energies, precipitate antisite defects, and vacancy migration. These NNPs can be further enhanced with additional structures, but the current results appear broadly accurate for many 
metallurgical problems. Along with the NNPs generated here, the DFT database here is also openly available for use with other ML methods on materials cloud [51] where we have uploaded all the DFT from the prior Al-Mg-Si study [52] as well as all DFT unique to this study [53].

Using these NNPs, we have demonstrated several metallurgical aspects critical in the processing and performance of $\mathrm{Al}-\mathrm{Mg}-\mathrm{Si}$ alloys. First, the NNPs have been used to compute the entire GSFE surfaces for the relevant slip planes of in situ $\beta^{\prime \prime}$ precipitates, with postvalidation by DFT at slip corresponding to the Burgers vectors of dislocations in Al. We are not aware of any other accurate shearing energies for any precipitates in any $\mathrm{Al}$ alloys (and few, if any, other alloys) using traditional potentials. This will enable the study of fully atomistic precipitate shearing and hence strengthening in these alloys. Second, we have examined the early stage clustering of solutes in Al-6xxx alloy under natural aging conditions. We show solute clustering and vacancy trapping with energies, timescales, and length scales that are consistent with deductions from experimental observations, with postvalidation by DFT of several complex clusters. We believe this is the first interatomic potential capable of accurately predicting early stage age-hardening kinetics in $\mathrm{Al}$ alloys, and which then remains suitable for further studies of mechanical performance versus aging.

The NNPs are not perfect. For instance, we find a non-negligible error in the $C_{44}$ for $\mathrm{Al}$, some deviations in low-energy antisite defects in $\beta^{\prime \prime}$ precipitates, and require the added repulsive potential to avoid artifacts at small atomic separations. However, there are paths to reduce or eliminate errors through further structural data, improved selection of symmetry functions, use of new classes of symmetry functions, training on energy differences rather than absolute energies, improved optimization strategies, and other machine learning methods beyond NNPs. Nonetheless, the overall performance of these potentials for a complex ternary alloy with complex precipitate phases remains impressive and generally far exceeds the capabilities of traditional potentials for binary alloys. The approach and methodology are not limited to Al$\mathrm{Mg}-\mathrm{Si}$ and so the success here points toward a bright future for accurate, predictive computational metallurgy using machine learning interatomic potentials.

\section{ACKNOWLEDGMENTS}

The authors acknowledge support for this work by the NCCR MARVEL, funded by the Swiss National Science Foundation. A.G. acknowledges support from the SNF Flexibility Grant. The authors would also like to thank Dr. G. Pizzi and Dr. S. Huber for their help in employing AiiDA.

\section{APPENDIX A}

\section{Addition of a short-range repulsive potential to the NNP}

As discussed in the main text, the major errors in the NNP are found for very close atomic distances. In this short-range domain, the NNP energies can become strongly negative, driving the system to collapse toward zero atomic spacings. Since the potentials are repulsive at larger distances, such short distances would rarely, if ever, be present in most applications governed by thermodynamics. However, when atoms are placed in positions a priori, such as in defining an initial path for a transition state analysis or an initial configuration for computing a fault energy, atoms can be placed close together and the serious failure of the NNP can lead to problems for these types of applications. To avoid pathological results, in principle, more structures with close atom spacings could be added to the set of training structures. Because these structures would have high energy, they could adversely affect the quality of the NNP in the domains of physical interest. Another solution, demonstrated here, is to simply add an ad hoc repulsive cut-and-shifted Lennard-Jones (LJ) potential at short distances to counteract the deficiencies of the NNP.

Specifically, we introduce a cut-and-shifted LJ potential to create a purely repulsive potential. The potential between atoms $i$ and $j$ at distance $r$ is taken to be

$$
L J_{i, j}(r)= \begin{cases}4 \epsilon\left[\left(\frac{\sigma_{i, j}}{r}\right)^{12}-\left(\frac{\sigma_{i, j}}{r}\right)^{6}\right]+4 \epsilon, & r \leqslant r_{\text {cut }} \\ 0, & r>r_{\text {cut }}\end{cases}
$$

where $r_{\text {cut }}=2^{\frac{1}{6}} \sigma$. For a ternary alloy, we have six LJ functions, and we use a common energy scale $\epsilon=20(\mathrm{eV})$ and pair-specific distances $\sigma_{i, j}$. We choose $r_{\text {cut }}=0.85 r_{0, i j}$ where $r_{0, i j} j=i$ is the bulk interatomic distance for atom $i$ given in the ASE [43] package. For unlike pairs $j \neq i$, we use $r_{0, i j}=0.5\left(r_{0, i i}+r_{0, j j}\right.$.

Figure 14 shows benchmark results equation-of-state (EOS) results for $\mathrm{Al}, \mathrm{Mg}, \mathrm{Si}, \beta^{\prime \prime}$, and $\beta^{\prime}$. In all cases, the $\mathrm{LJ}$ addition leads to a strongly repulsive potential in regimes
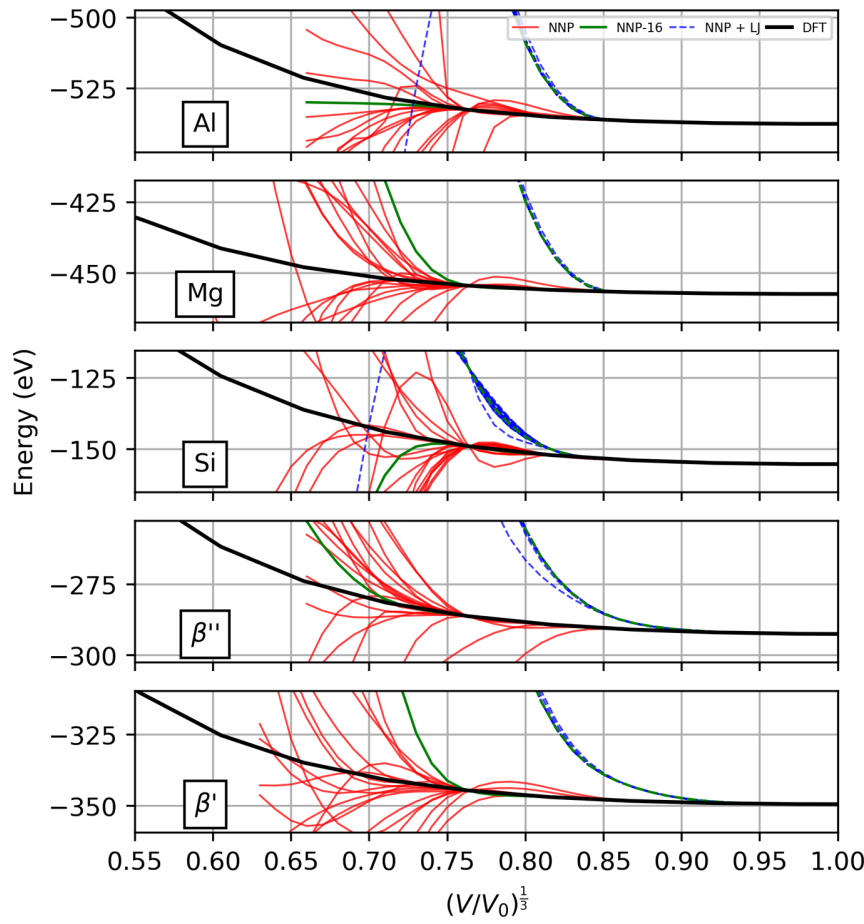

FIG. 14. Equation of state for key structures as predicted by the various NNPs with and without the additional repulsive potential. The DFT reference data is shown along with the specific behavior of NNP16 used in the main text. 
where the NNP may show softening or become attractive, both unphysical. The LJ correction leads to significant deviations from the DFT data, but that remains largely irrelevant since these domains are not accessed in most simulations. Other machine learning methods, such as the PINN potential [4] or differential $(\Delta)$ learning methods [54] would likely be better.
However, the present LJ term easily and efficiently resolves the severe issues with the NNP and is easily and efficiently implemented in, for instance, the LAMMPS code.

\section{Full table for $\beta^{\prime \prime}$ parameters}

Table III shows compiled results for the $\beta^{\prime \prime}$ phase.

TABLE III. Statistics for material properties of the $\beta^{\prime \prime}$ phases.

\begin{tabular}{|c|c|c|c|c|c|c|c|c|c|c|c|c|}
\hline & \multicolumn{4}{|c|}{$\mathrm{Mg}_{5} \mathrm{Al}_{2} \mathrm{Si}_{4}$} & \multicolumn{4}{|c|}{$\mathrm{Mg}_{5} \mathrm{Si}_{6}$} & \multicolumn{4}{|c|}{$\mathrm{Mg}_{4} \mathrm{Al}_{3} \mathrm{Si}_{4}$} \\
\hline & DFT & NNP16 & AVG & STD & DFT & NNP16 & AVG & STD & DFT & NNP16 & AVG & STD \\
\hline $\operatorname{Vol}\left(\AA^{3}\right)$ & 18.49 & 18.45 & 18.46 & 0.01 & 18.20 & 18.06 & 18.17 & 0.03 & 17.98 & 17.91 & 17.94 & 0.01 \\
\hline $\mathrm{a}(\AA)$ & 15.34 & 15.35 & 15.33 & 0.02 & 15.12 & 15.34 & 15.25 & 0.03 & 15.12 & 15.13 & 15.14 & 0.02 \\
\hline $\mathrm{b}(\AA)$ & 4.06 & 4.03 & 4.04 & 0.01 & 4.08 & 3.96 & 4.04 & 0.03 & 4.13 & 4.08 & 4.08 & 0.01 \\
\hline$c(\AA)$ & 6.79 & 6.81 & 6.81 & 0.01 & 6.93 & 6.93 & 6.90 & 0.02 & 6.61 & 6.64 & 6.64 & 0.01 \\
\hline$\alpha$ & 90.00 & 90.00 & 90.00 & 0.00 & 90.00 & 90.00 & 90.00 & 0.00 & 90.00 & 90.00 & 90.00 & 0.00 \\
\hline$\beta$ & 105.93 & 105.57 & 105.65 & 0.13 & 110.20 & 109.24 & 109.97 & 0.32 & 106.61 & 105.95 & 105.97 & 0.13 \\
\hline$\gamma$ & 90.00 & 90.00 & 90.00 & 0.00 & 90.00 & 90.00 & 90.00 & 0.00 & 90.00 & 90.00 & 90.00 & 0.00 \\
\hline $\mathrm{C}_{11}(\mathrm{GPa})$ & 108.38 & 113.95 & 109.74 & 1.80 & 105.76 & 104.21 & 103.70 & 5.12 & 114.18 & 114.49 & 113.43 & 1.45 \\
\hline $\mathrm{C}_{22}(\mathrm{GPa})$ & 94.82 & 93.08 & 92.08 & 3.36 & 90.18 & 81.91 & 78.42 & 5.80 & 104.49 & 95.52 & 89.91 & 2.50 \\
\hline $\mathrm{C}_{33}(\mathrm{GPa})$ & 99.93 & 96.15 & 95.44 & 1.68 & 87.50 & 84.26 & 81.19 & 4.61 & 103.91 & 108.18 & 103.47 & 1.67 \\
\hline $\mathrm{C}_{44}(\mathrm{GPa})$ & 23.02 & 26.46 & 25.30 & 1.15 & 16.89 & 20.38 & 21.70 & 1.56 & 21.49 & 27.09 & 23.99 & 1.00 \\
\hline $\mathrm{C}_{55}(\mathrm{GPa})$ & 33.35 & 34.31 & 32.96 & 1.07 & 32.83 & 24.50 & 26.67 & 1.09 & 34.26 & 32.86 & 31.49 & 1.03 \\
\hline $\mathrm{C}_{66}(\mathrm{GPa})$ & 27.06 & 31.52 & 30.32 & 0.78 & 30.33 & 31.58 & 30.05 & 1.32 & 23.30 & 31.45 & 30.31 & 1.01 \\
\hline $\mathrm{C}_{12}(\mathrm{GPa})$ & 42.28 & 45.61 & 45.15 & 1.82 & 49.24 & 63.53 & 60.42 & 2.98 & 45.87 & 49.07 & 51.10 & 2.43 \\
\hline $\mathrm{C}_{13}(\mathrm{GPa})$ & 47.66 & 47.92 & 46.30 & 1.53 & 50.07 & 48.96 & 46.52 & 3.29 & 47.76 & 49.62 & 46.95 & 1.77 \\
\hline $\mathrm{C}_{23}(\mathrm{GPa})$ & 46.39 & 38.91 & 39.00 & 2.40 & 46.36 & 44.70 & 42.38 & 2.14 & 48.90 & 44.23 & 44.28 & 2.82 \\
\hline $\mathrm{C}_{15}(\mathrm{GPa})$ & -2.66 & -3.64 & -4.81 & 1.71 & -10.79 & -8.34 & -4.82 & 2.26 & -4.11 & -5.01 & -3.09 & 2.05 \\
\hline $\mathrm{C}_{25}(\mathrm{GPa})$ & 4.52 & 1.66 & 3.64 & 1.70 & 6.16 & 1.69 & 4.03 & 1.45 & 5.87 & 1.37 & 4.55 & 1.83 \\
\hline $\mathrm{C}_{35}(\mathrm{GPa})$ & 3.08 & 2.77 & 2.78 & 1.34 & 8.76 & 4.18 & 4.44 & 1.18 & 6.56 & 4.08 & 6.24 & 1.07 \\
\hline $\mathrm{C}_{46}(\mathrm{GPa})$ & 4.16 & 2.42 & 3.76 & 0.69 & 1.42 & 9.11 & 6.09 & 0.64 & -0.12 & 2.20 & 3.46 & 0.65 \\
\hline
\end{tabular}


3. Symmetry function hyperparameters

Here we show full symmetry function hyperparameters Table IV shows the 2-Body terms and Table V shows the 3-Body terms.

TABLE IV. Hyperparameters for the radial symmetry functions.

\begin{tabular}{|c|c|c|c|c|}
\hline Element 1 & Element 2 & $\eta$ & $r_{2}$ & $r_{c}$ \\
\hline $\mathrm{Al}$ & $\mathrm{Al}$ & 0.003 & 0.000 & 20.000 \\
\hline $\mathrm{Al}$ & $\mathrm{Al}$ & 0.016 & 0.000 & 16.000 \\
\hline $\mathrm{Al}$ & $\mathrm{Al}$ & 0.016 & 0.000 & 8.000 \\
\hline $\mathrm{Al}$ & $\mathrm{Al}$ & 0.045 & 11.314 & 16.000 \\
\hline $\mathrm{Al}$ & $\mathrm{Al}$ & 0.058 & 10.000 & 20.000 \\
\hline $\mathrm{Al}$ & $\mathrm{Al}$ & 0.062 & 0.000 & 8.000 \\
\hline $\mathrm{Al}$ & $\mathrm{Al}$ & 0.071 & 16.259 & 20.000 \\
\hline $\mathrm{Al}$ & $\mathrm{Al}$ & 0.091 & 8.000 & 16.000 \\
\hline $\mathrm{Al}$ & $\mathrm{Al}$ & 0.108 & 13.218 & 20.000 \\
\hline $\mathrm{Al}$ & $\mathrm{Al}$ & 0.112 & 13.007 & 16.000 \\
\hline $\mathrm{Al}$ & $\mathrm{Al}$ & 0.124 & 0.000 & 8.000 \\
\hline $\mathrm{Al}$ & $\mathrm{Mg}$ & 0.003 & 0.000 & 20.000 \\
\hline $\mathrm{Al}$ & $\mathrm{Mg}$ & 0.016 & 0.000 & 16.000 \\
\hline $\mathrm{Al}$ & $\mathrm{Mg}$ & 0.016 & 0.000 & 8.000 \\
\hline $\mathrm{Al}$ & $\mathrm{Mg}$ & 0.036 & 0.000 & 8.000 \\
\hline $\mathrm{Al}$ & $\mathrm{Mg}$ & 0.058 & 10.000 & 20.000 \\
\hline $\mathrm{Al}$ & $\mathrm{Mg}$ & 0.071 & 16.259 & 20.000 \\
\hline $\mathrm{Al}$ & $\mathrm{Mg}$ & 0.082 & 0.000 & 8.000 \\
\hline $\mathrm{Al}$ & $\mathrm{Mg}$ & 0.091 & 8.000 & 16.000 \\
\hline $\mathrm{Al}$ & $\mathrm{Mg}$ & 0.108 & 13.218 & 20.000 \\
\hline $\mathrm{Al}$ & $\mathrm{Mg}$ & 0.112 & 13.007 & 16.000 \\
\hline $\mathrm{Al}$ & $\mathrm{Mg}$ & 0.117 & 7.071 & 20.000 \\
\hline $\mathrm{Al}$ & $\mathrm{Si}$ & 0.003 & 0.000 & 20.000 \\
\hline $\mathrm{Al}$ & $\mathrm{Si}$ & 0.016 & 0.000 & 16.000 \\
\hline $\mathrm{Al}$ & $\mathrm{Si}$ & 0.016 & 0.000 & 8.000 \\
\hline $\mathrm{Al}$ & $\mathrm{Si}$ & 0.058 & 10.000 & 20.000 \\
\hline $\mathrm{Al}$ & $\mathrm{Si}$ & 0.071 & 16.259 & 20.000 \\
\hline $\mathrm{Al}$ & $\mathrm{Si}$ & 0.082 & 0.000 & 8.000 \\
\hline $\mathrm{Al}$ & $\mathrm{Si}$ & 0.091 & 8.000 & 16.000 \\
\hline $\mathrm{Al}$ & $\mathrm{Si}$ & 0.108 & 13.218 & 20.000 \\
\hline $\mathrm{Al}$ & $\mathrm{Si}$ & 0.112 & 13.007 & 16.000 \\
\hline $\mathrm{Al}$ & $\mathrm{Si}$ & 0.117 & 7.071 & 20.000 \\
\hline $\mathrm{Mg}$ & $\mathrm{Al}$ & 0.003 & 0.000 & 20.000 \\
\hline $\mathrm{Mg}$ & $\mathrm{Al}$ & 0.016 & 0.000 & 16.000 \\
\hline $\mathrm{Mg}$ & $\mathrm{Al}$ & 0.016 & 0.000 & 8.000 \\
\hline $\mathrm{Mg}$ & $\mathrm{Al}$ & 0.036 & 0.000 & 8.000 \\
\hline $\mathrm{Mg}$ & $\mathrm{Al}$ & 0.058 & 10.000 & 20.000 \\
\hline $\mathrm{Mg}$ & $\mathrm{Al}$ & 0.071 & 16.259 & 20.000 \\
\hline $\mathrm{Mg}$ & $\mathrm{Al}$ & 0.082 & 0.000 & 8.000 \\
\hline $\mathrm{Mg}$ & $\mathrm{Al}$ & 0.091 & 8.000 & 16.000 \\
\hline $\mathrm{Mg}$ & $\mathrm{Al}$ & 0.108 & 13.218 & 20.000 \\
\hline $\mathrm{Mg}$ & $\mathrm{Al}$ & 0.112 & 13.007 & 16.000 \\
\hline $\mathrm{Mg}$ & $\mathrm{Mg}$ & 0.003 & 0.000 & 20.000 \\
\hline $\mathrm{Mg}$ & $\mathrm{Mg}$ & 0.016 & 0.000 & 16.000 \\
\hline $\mathrm{Mg}$ & $\mathrm{Mg}$ & 0.016 & 0.000 & 8.000 \\
\hline $\mathrm{Mg}$ & $\mathrm{Mg}$ & 0.045 & 11.314 & 16.000 \\
\hline $\mathrm{Mg}$ & $\mathrm{Mg}$ & 0.058 & 10.000 & 20.000 \\
\hline
\end{tabular}

TABLE IV. (Continued).

\begin{tabular}{|c|c|c|c|c|}
\hline Element 1 & Element 2 & $\eta$ & $r_{2}$ & $r_{c}$ \\
\hline $\mathrm{Mg}$ & $\mathrm{Mg}$ & 0.062 & 0.000 & 8.000 \\
\hline $\mathrm{Mg}$ & $\mathrm{Mg}$ & 0.071 & 16.259 & 20.000 \\
\hline $\mathrm{Mg}$ & $\mathrm{Mg}$ & 0.091 & 8.000 & 16.000 \\
\hline $\mathrm{Mg}$ & $\mathrm{Mg}$ & 0.108 & 13.218 & 20.000 \\
\hline $\mathrm{Mg}$ & $\mathrm{Mg}$ & 0.112 & 13.007 & 16.000 \\
\hline $\mathrm{Mg}$ & $\mathrm{Mg}$ & 0.117 & 7.071 & 20.000 \\
\hline $\mathrm{Mg}$ & $\mathrm{Mg}$ & 0.124 & 0.000 & 8.000 \\
\hline $\mathrm{Mg}$ & $\mathrm{Si}$ & 0.003 & 0.000 & 20.000 \\
\hline $\mathrm{Mg}$ & $\mathrm{Si}$ & 0.016 & 0.000 & 16.000 \\
\hline $\mathrm{Mg}$ & $\mathrm{Si}$ & 0.016 & 0.000 & 8.000 \\
\hline $\mathrm{Mg}$ & $\mathrm{Si}$ & 0.029 & 14.142 & 20.000 \\
\hline $\mathrm{Mg}$ & $\mathrm{Si}$ & 0.036 & 0.000 & 8.000 \\
\hline $\mathrm{Mg}$ & $\mathrm{Si}$ & 0.045 & 11.314 & 16.000 \\
\hline $\mathrm{Mg}$ & $\mathrm{Si}$ & 0.071 & 16.259 & 20.000 \\
\hline $\mathrm{Mg}$ & $\mathrm{Si}$ & 0.082 & 0.000 & 8.000 \\
\hline $\mathrm{Mg}$ & $\mathrm{Si}$ & 0.108 & 13.218 & 20.000 \\
\hline $\mathrm{Mg}$ & $\mathrm{Si}$ & 0.112 & 13.007 & 16.000 \\
\hline $\mathrm{Mg}$ & $\mathrm{Si}$ & 0.117 & 7.071 & 20.000 \\
\hline $\mathrm{Si}$ & $\mathrm{Al}$ & 0.003 & 0.000 & 20.000 \\
\hline $\mathrm{Si}$ & $\mathrm{Al}$ & 0.016 & 0.000 & 16.000 \\
\hline $\mathrm{Si}$ & $\mathrm{Al}$ & 0.016 & 0.000 & 8.000 \\
\hline $\mathrm{Si}$ & $\mathrm{Al}$ & 0.071 & 16.259 & 20.000 \\
\hline $\mathrm{Si}$ & $\mathrm{Al}$ & 0.082 & 0.000 & 8.000 \\
\hline $\mathrm{Si}$ & $\mathrm{Al}$ & 0.091 & 8.000 & 16.000 \\
\hline $\mathrm{Si}$ & $\mathrm{Al}$ & 0.108 & 13.218 & 20.000 \\
\hline $\mathrm{Si}$ & $\mathrm{Al}$ & 0.112 & 13.007 & 16.000 \\
\hline $\mathrm{Si}$ & $\mathrm{Mg}$ & 0.003 & 0.000 & 20.000 \\
\hline $\mathrm{Si}$ & $\mathrm{Mg}$ & 0.016 & 0.000 & 16.000 \\
\hline $\mathrm{Si}$ & $\mathrm{Mg}$ & 0.016 & 0.000 & 8.000 \\
\hline $\mathrm{Si}$ & $\mathrm{Mg}$ & 0.058 & 10.000 & 20.000 \\
\hline $\mathrm{Si}$ & $\mathrm{Mg}$ & 0.071 & 16.259 & 20.000 \\
\hline $\mathrm{Si}$ & $\mathrm{Mg}$ & 0.082 & 0.000 & 8.000 \\
\hline $\mathrm{Si}$ & $\mathrm{Mg}$ & 0.091 & 8.000 & 16.000 \\
\hline $\mathrm{Si}$ & $\mathrm{Mg}$ & 0.108 & 13.218 & 20.000 \\
\hline $\mathrm{Si}$ & $\mathrm{Mg}$ & 0.112 & 13.007 & 16.000 \\
\hline $\mathrm{Si}$ & $\mathrm{Mg}$ & 0.117 & 7.071 & 20.000 \\
\hline $\mathrm{Si}$ & $\mathrm{Si}$ & 0.003 & 0.000 & 20.000 \\
\hline $\mathrm{Si}$ & $\mathrm{Si}$ & 0.016 & 0.000 & 8.000 \\
\hline $\mathrm{Si}$ & $\mathrm{Si}$ & 0.021 & 0.000 & 16.000 \\
\hline $\mathrm{Si}$ & $\mathrm{Si}$ & 0.036 & 0.000 & 8.000 \\
\hline $\mathrm{Si}$ & $\mathrm{Si}$ & 0.058 & 10.000 & 20.000 \\
\hline $\mathrm{Si}$ & $\mathrm{Si}$ & 0.071 & 16.259 & 20.000 \\
\hline $\mathrm{Si}$ & $\mathrm{Si}$ & 0.082 & 0.000 & 8.000 \\
\hline $\mathrm{Si}$ & $\mathrm{Si}$ & 0.091 & 8.000 & 16.000 \\
\hline $\mathrm{Si}$ & $\mathrm{Si}$ & 0.108 & 13.218 & 20.000 \\
\hline $\mathrm{Si}$ & $\mathrm{Si}$ & 0.112 & 13.007 & 16.000 \\
\hline $\mathrm{Si}$ & $\mathrm{Si}$ & 0.117 & 7.071 & 20.000 \\
\hline $\mathrm{Si}$ & $\mathrm{Si}$ & 0.124 & 0.000 & 8.000 \\
\hline
\end{tabular}


TABLE V. Hyperparameters for the angular symmetry functions.

\begin{tabular}{|c|c|c|c|c|c|c|}
\hline Element 1 & Element 2 & Element 3 & $\eta$ & $\lambda$ & $\zeta$ & $r_{c}$ \\
\hline $\mathrm{Si}$ & $\mathrm{Al}$ & $\mathrm{Al}$ & 0.007 & -1.000 & 1.000 & 12.000 \\
\hline $\mathrm{Si}$ & $\mathrm{Al}$ & $\mathrm{Al}$ & 0.007 & 1.000 & 1.000 & 12.000 \\
\hline $\mathrm{Si}$ & $\mathrm{Al}$ & $\mathrm{Al}$ & 0.016 & 1.000 & 1.000 & 8.000 \\
\hline $\mathrm{Si}$ & $\mathrm{Al}$ & $\mathrm{Si}$ & 0.007 & -1.000 & 1.000 & 12.000 \\
\hline $\mathrm{Si}$ & $\mathrm{Al}$ & $\mathrm{Si}$ & 0.007 & 1.000 & 1.000 & 12.000 \\
\hline $\mathrm{Si}$ & $\mathrm{Al}$ & $\mathrm{Si}$ & 0.007 & 1.000 & 4.000 & 12.000 \\
\hline $\mathrm{Si}$ & $\mathrm{Al}$ & $\mathrm{Si}$ & 0.016 & 1.000 & 1.000 & 8.000 \\
\hline $\mathrm{Si}$ & $\mathrm{Al}$ & $\mathrm{Si}$ & 0.020 & 1.000 & 4.000 & 12.000 \\
\hline $\mathrm{Si}$ & $\mathrm{Mg}$ & $\mathrm{Al}$ & 0.007 & -1.000 & 1.000 & 12.000 \\
\hline $\mathrm{Si}$ & $\mathrm{Mg}$ & $\mathrm{Al}$ & 0.007 & -1.000 & 4.000 & 12.000 \\
\hline $\mathrm{Si}$ & $\mathrm{Mg}$ & $\mathrm{Al}$ & 0.007 & 1.000 & 1.000 & 12.000 \\
\hline $\mathrm{Si}$ & $\mathrm{Mg}$ & $\mathrm{Al}$ & 0.020 & 1.000 & 1.000 & 12.000 \\
\hline $\mathrm{Si}$ & $\mathrm{Mg}$ & $\mathrm{Mg}$ & 0.007 & -1.000 & 1.000 & 12.000 \\
\hline $\mathrm{Si}$ & $\mathrm{Mg}$ & $\mathrm{Mg}$ & 0.007 & -1.000 & 4.000 & 12.000 \\
\hline $\mathrm{Si}$ & $\mathrm{Mg}$ & $\mathrm{Mg}$ & 0.007 & 1.000 & 1.000 & 12.000 \\
\hline $\mathrm{Si}$ & $\mathrm{Mg}$ & $\mathrm{Mg}$ & 0.007 & 1.000 & 4.000 & 12.000 \\
\hline $\mathrm{Si}$ & $\mathrm{Mg}$ & $\mathrm{Mg}$ & 0.020 & -1.000 & 1.000 & 12.000 \\
\hline $\mathrm{Si}$ & $\mathrm{Mg}$ & $\mathrm{Mg}$ & 0.020 & 1.000 & 1.000 & 12.000 \\
\hline $\mathrm{Si}$ & $\mathrm{Mg}$ & $\mathrm{Si}$ & 0.007 & -1.000 & 1.000 & 12.000 \\
\hline $\mathrm{Si}$ & $\mathrm{Mg}$ & $\mathrm{Si}$ & 0.007 & -1.000 & 4.000 & 12.000 \\
\hline $\mathrm{Si}$ & $\mathrm{Mg}$ & $\mathrm{Si}$ & 0.007 & 1.000 & 1.000 & 12.000 \\
\hline $\mathrm{Si}$ & $\mathrm{Mg}$ & $\mathrm{Si}$ & 0.007 & 1.000 & 4.000 & 12.000 \\
\hline $\mathrm{Si}$ & $\mathrm{Mg}$ & $\mathrm{Si}$ & 0.016 & 1.000 & 1.000 & 8.000 \\
\hline $\mathrm{Si}$ & $\mathrm{Mg}$ & $\mathrm{Si}$ & 0.020 & -1.000 & 1.000 & 12.000 \\
\hline $\mathrm{Si}$ & $\mathrm{Mg}$ & $\mathrm{Si}$ & 0.020 & 1.000 & 1.000 & 12.000 \\
\hline $\mathrm{Si}$ & $\mathrm{Si}$ & $\mathrm{Si}$ & 0.007 & -1.000 & 2.000 & 12.000 \\
\hline $\mathrm{Si}$ & $\mathrm{Si}$ & $\mathrm{Si}$ & 0.007 & -1.000 & 4.000 & 12.000 \\
\hline $\mathrm{Si}$ & $\mathrm{Si}$ & $\mathrm{Si}$ & 0.007 & 1.000 & 1.000 & 12.000 \\
\hline $\mathrm{Si}$ & $\mathrm{Si}$ & $\mathrm{Si}$ & 0.007 & 1.000 & 4.000 & 12.000 \\
\hline $\mathrm{Si}$ & $\mathrm{Si}$ & $\mathrm{Si}$ & 0.016 & -1.000 & 2.000 & 8.000 \\
\hline $\mathrm{Si}$ & $\mathrm{Si}$ & $\mathrm{Si}$ & 0.016 & 1.000 & 1.000 & 8.000 \\
\hline $\mathrm{Si}$ & $\mathrm{Si}$ & $\mathrm{Si}$ & 0.016 & 1.000 & 8.000 & 8.000 \\
\hline $\mathrm{Si}$ & $\mathrm{Si}$ & $\mathrm{Si}$ & 0.020 & -1.000 & 1.000 & 12.000 \\
\hline $\mathrm{Si}$ & $\mathrm{Si}$ & $\mathrm{Si}$ & 0.020 & 1.000 & 1.000 & 12.000 \\
\hline $\mathrm{Al}$ & $\mathrm{Al}$ & $\mathrm{Al}$ & 0.007 & -1.000 & 1.000 & 12.000 \\
\hline Al & $\mathrm{Al}$ & $\mathrm{Al}$ & 0.007 & 1.000 & 1.000 & 12.000 \\
\hline Al & $\mathrm{Al}$ & $\mathrm{Al}$ & 0.007 & 1.000 & 4.000 & 12.000 \\
\hline $\mathrm{Al}$ & $\mathrm{Al}$ & $\mathrm{Al}$ & 0.016 & -1.000 & 1.000 & 8.000 \\
\hline Al & $\mathrm{Al}$ & $\mathrm{Al}$ & 0.016 & 1.000 & 1.000 & 8.000 \\
\hline $\mathrm{Al}$ & $\mathrm{Al}$ & $\mathrm{Si}$ & 0.007 & -1.000 & 1.000 & 12.000 \\
\hline $\mathrm{Al}$ & $\mathrm{Al}$ & $\mathrm{Si}$ & 0.007 & 1.000 & 1.000 & 12.000 \\
\hline Al & $\mathrm{Al}$ & $\mathrm{Si}$ & 0.007 & 1.000 & 4.000 & 12.000 \\
\hline $\mathrm{Al}$ & $\mathrm{Al}$ & $\mathrm{Si}$ & 0.016 & 1.000 & 1.000 & 8.000 \\
\hline $\mathrm{Al}$ & $\mathrm{Al}$ & $\mathrm{Si}$ & 0.020 & 1.000 & 1.000 & 12.000 \\
\hline $\mathrm{Al}$ & $\mathrm{Mg}$ & $\mathrm{Al}$ & 0.007 & -1.000 & 1.000 & 12.000 \\
\hline $\mathrm{Al}$ & $\mathrm{Mg}$ & $\mathrm{Al}$ & 0.007 & 1.000 & 1.000 & 12.000 \\
\hline Al & $\mathrm{Mg}$ & $\mathrm{Al}$ & 0.007 & 1.000 & 4.000 & 12.000 \\
\hline $\mathrm{Al}$ & $\mathrm{Mg}$ & $\mathrm{Al}$ & 0.016 & 1.000 & 1.000 & 8.000 \\
\hline $\mathrm{Al}$ & $\mathrm{Mg}$ & $\mathrm{Al}$ & 0.020 & 1.000 & 2.000 & 12.000 \\
\hline $\mathrm{Al}$ & $\mathrm{Mg}$ & $\mathrm{Mg}$ & 0.007 & -1.000 & 1.000 & 12.000 \\
\hline
\end{tabular}

TABLE V. (Continued).

\begin{tabular}{|c|c|c|c|c|c|c|}
\hline Element 1 & Element 2 & Element 3 & $\eta$ & $\lambda$ & $\zeta$ & $r_{c}$ \\
\hline $\mathrm{Al}$ & $\mathrm{Mg}$ & $\mathrm{Mg}$ & 0.007 & -1.000 & 4.000 & 12.000 \\
\hline $\mathrm{Al}$ & $\mathrm{Mg}$ & $\mathrm{Mg}$ & 0.007 & 1.000 & 1.000 & 12.000 \\
\hline $\mathrm{Al}$ & $\mathrm{Mg}$ & $\mathrm{Mg}$ & 0.007 & 1.000 & 4.000 & 12.000 \\
\hline $\mathrm{Al}$ & $\mathrm{Mg}$ & $\mathrm{Mg}$ & 0.020 & 1.000 & 1.000 & 12.000 \\
\hline $\mathrm{Al}$ & $\mathrm{Mg}$ & $\mathrm{Si}$ & 0.007 & -1.000 & 1.000 & 12.000 \\
\hline $\mathrm{Al}$ & $\mathrm{Mg}$ & $\mathrm{Si}$ & 0.007 & -1.000 & 4.000 & 12.000 \\
\hline $\mathrm{Al}$ & $\mathrm{Mg}$ & $\mathrm{Si}$ & 0.007 & 1.000 & 1.000 & 12.000 \\
\hline $\mathrm{Al}$ & $\mathrm{Mg}$ & $\mathrm{Si}$ & 0.007 & 1.000 & 4.000 & 12.000 \\
\hline $\mathrm{Al}$ & $\mathrm{Mg}$ & $\mathrm{Si}$ & 0.020 & 1.000 & 1.000 & 12.000 \\
\hline $\mathrm{Al}$ & $\mathrm{Si}$ & $\mathrm{Si}$ & 0.007 & -1.000 & 1.000 & 12.000 \\
\hline $\mathrm{Al}$ & $\mathrm{Si}$ & $\mathrm{Si}$ & 0.007 & -1.000 & 4.000 & 12.000 \\
\hline $\mathrm{Al}$ & $\mathrm{Si}$ & $\mathrm{Si}$ & 0.007 & 1.000 & 1.000 & 12.000 \\
\hline $\mathrm{Al}$ & $\mathrm{Si}$ & $\mathrm{Si}$ & 0.007 & 1.000 & 4.000 & 12.000 \\
\hline $\mathrm{Al}$ & $\mathrm{Si}$ & $\mathrm{Si}$ & 0.016 & 1.000 & 1.000 & 8.000 \\
\hline $\mathrm{Al}$ & $\mathrm{Si}$ & $\mathrm{Si}$ & 0.020 & -1.000 & 1.000 & 12.000 \\
\hline $\mathrm{Al}$ & $\mathrm{Si}$ & $\mathrm{Si}$ & 0.020 & 1.000 & 2.000 & 12.000 \\
\hline $\mathrm{Mg}$ & $\mathrm{Al}$ & $\mathrm{Al}$ & 0.007 & -1.000 & 1.000 & 12.000 \\
\hline $\mathrm{Mg}$ & $\mathrm{Al}$ & $\mathrm{Al}$ & 0.007 & 1.000 & 1.000 & 12.000 \\
\hline $\mathrm{Mg}$ & $\mathrm{Al}$ & $\mathrm{Al}$ & 0.007 & 1.000 & 4.000 & 12.000 \\
\hline $\mathrm{Mg}$ & $\mathrm{Al}$ & $\mathrm{Al}$ & 0.016 & 1.000 & 1.000 & 8.000 \\
\hline $\mathrm{Mg}$ & $\mathrm{Al}$ & $\mathrm{Si}$ & 0.007 & -1.000 & 1.000 & 12.000 \\
\hline $\mathrm{Mg}$ & $\mathrm{Al}$ & $\mathrm{Si}$ & 0.007 & 1.000 & 1.000 & 12.000 \\
\hline $\mathrm{Mg}$ & $\mathrm{Al}$ & $\mathrm{Si}$ & 0.007 & 1.000 & 4.000 & 12.000 \\
\hline $\mathrm{Mg}$ & $\mathrm{Al}$ & $\mathrm{Si}$ & 0.020 & 1.000 & 1.000 & 12.000 \\
\hline $\mathrm{Mg}$ & $\mathrm{Mg}$ & $\mathrm{Al}$ & 0.007 & -1.000 & 1.000 & 12.000 \\
\hline $\mathrm{Mg}$ & $\mathrm{Mg}$ & $\mathrm{Al}$ & 0.007 & 1.000 & 1.000 & 12.000 \\
\hline $\mathrm{Mg}$ & $\mathrm{Mg}$ & $\mathrm{Al}$ & 0.007 & 1.000 & 4.000 & 12.000 \\
\hline $\mathrm{Mg}$ & $\mathrm{Mg}$ & $\mathrm{Al}$ & 0.020 & 1.000 & 1.000 & 12.000 \\
\hline $\mathrm{Mg}$ & $\mathrm{Mg}$ & $\mathrm{Mg}$ & 0.007 & -1.000 & 1.000 & 12.000 \\
\hline $\mathrm{Mg}$ & $\mathrm{Mg}$ & $\mathrm{Mg}$ & 0.007 & -1.000 & 4.000 & 12.000 \\
\hline $\mathrm{Mg}$ & $\mathrm{Mg}$ & $\mathrm{Mg}$ & 0.007 & 1.000 & 1.000 & 12.000 \\
\hline $\mathrm{Mg}$ & $\mathrm{Mg}$ & $\mathrm{Mg}$ & 0.007 & 1.000 & 4.000 & 12.000 \\
\hline $\mathrm{Mg}$ & $\mathrm{Mg}$ & $\mathrm{Mg}$ & 0.020 & 1.000 & 1.000 & 12.000 \\
\hline $\mathrm{Mg}$ & $\mathrm{Mg}$ & $\mathrm{Si}$ & 0.007 & -1.000 & 1.000 & 12.000 \\
\hline $\mathrm{Mg}$ & $\mathrm{Mg}$ & $\mathrm{Si}$ & 0.007 & -1.000 & 4.000 & 12.000 \\
\hline $\mathrm{Mg}$ & $\mathrm{Mg}$ & $\mathrm{Si}$ & 0.007 & 1.000 & 1.000 & 12.000 \\
\hline $\mathrm{Mg}$ & $\mathrm{Mg}$ & $\mathrm{Si}$ & 0.007 & 1.000 & 4.000 & 12.000 \\
\hline $\mathrm{Mg}$ & $\mathrm{Mg}$ & $\mathrm{Si}$ & 0.016 & 1.000 & 1.000 & 8.000 \\
\hline $\mathrm{Mg}$ & $\mathrm{Mg}$ & $\mathrm{Si}$ & 0.020 & -1.000 & 1.000 & 12.000 \\
\hline $\mathrm{Mg}$ & $\mathrm{Mg}$ & $\mathrm{Si}$ & 0.020 & 1.000 & 1.000 & 12.000 \\
\hline $\mathrm{Mg}$ & $\mathrm{Si}$ & $\mathrm{Si}$ & 0.007 & -1.000 & 1.000 & 12.000 \\
\hline $\mathrm{Mg}$ & $\mathrm{Si}$ & $\mathrm{Si}$ & 0.007 & -1.000 & 4.000 & 12.000 \\
\hline $\mathrm{Mg}$ & $\mathrm{Si}$ & $\mathrm{Si}$ & 0.007 & 1.000 & 1.000 & 12.000 \\
\hline $\mathrm{Mg}$ & $\mathrm{Si}$ & $\mathrm{Si}$ & 0.007 & 1.000 & 4.000 & 12.000 \\
\hline $\mathrm{Mg}$ & $\mathrm{Si}$ & $\mathrm{Si}$ & 0.016 & 1.000 & 1.000 & 8.000 \\
\hline $\mathrm{Mg}$ & $\mathrm{Si}$ & $\mathrm{Si}$ & 0.020 & -1.000 & 1.000 & 12.000 \\
\hline $\mathrm{Mg}$ & $\mathrm{Si}$ & $\mathrm{Si}$ & 0.020 & 1.000 & 4.000 & 12.000 \\
\hline
\end{tabular}

[1] A. P. Bartók, R. Kondor, and G. Csányi, On representing chemical environments, Phys. Rev. B - Condens. Matter Mater. Phys. 87, 184115 (2013).
[2] J. Behler, Constructing high-dimensional neural-network potentials: A tutorial review, Int. J. Quantum Chem. 115, 1032 (2015). 
[3] R. Kobayashi, D. Giofré, T. Junge, M. Ceriotti, and W. A. Curtin, Neural network potential for Al-Mg-Si alloys, Phys. Rev. Mater. 1, 053604 (2017).

[4] G. P. P. Pun, R. Batra, R. Ramprasad, and Y. Mishin, Physically informed artificial neural networks for atomistic modeling of materials, Nat. Commun. 10, 2339 (2019).

[5] Q. Wang, Z. Li, S. Pang, X. Li, C. Dong, P. Liaw, Q. Wang, Z. Li, S. Pang, X. Li, C. Dong, and P. K. Liaw, Coherent precipitation and strengthening in compositionally complex alloys: A review, Entropy 20, 878 (2018).

[6] M. Hodapp and A. Shapeev, In operando active learning of interatomic interaction during large-scale simulations, Mach. Learn.: Sci. Technol. 1, 045005 (2020).

[7] D. Marchand, A. Jain, A. Glensk, and W. A. Curtin, Machine learning for metallurgy I. A neural network potential for $\mathrm{Al}-\mathrm{Cu}$, Phys. Rev. Materials 4, 103601 (2020).

[8] M. Stricker, B. Yin, E. Mak, and W. A. Curtin, Machine learning for metallurgy II. A neural network potential for magnesium, Phys. Rev. Materials 4, 103602 (2020).

[9] W. J. Szlachta, A. P. Bartók, and G. Csányi, Accuracy and transferability of Gaussian approximation potential models for tungsten, Phys. Rev. B 90, 104108 (2014).

[10] J. Behler and M. Parrinello, Generalized Neural-Network Representation of High-Dimensional Potential-Energy Surfaces, Phys. Rev. Lett. 98, 146401 (2007).

[11] D. Rogers and M. Hahn, Extended-connectivity fingerprints, J. Chem. Inf. Model. 50, 742 (2010).

[12] A. P. Bartók and G. Csányi, Gaussian approximation potentials: A brief tutorial introduction, Int. J. Quantum Chem. 115, 1051 (2015).

[13] F. A. Faber, L. Hutchison, B. Huang, J. Gilmer, S. S. Schoenholz, G. E. Dahl, O. Vinyals, S. Kearnes, P. F. Riley, and O. A. V. Lilienfeld, Prediction errors of molecular machine learning models lower than hybrid DFT error, J. Chem. Theor. Comput. 13, 5255 (2017).

[14] M. A. Caro, G. Csányi, T. Laurila, and V. L. Deringer, Machine learning driven simulated deposition of carbon films: From lowdensity to diamondlike amorphous carbon, Phys. Rev. B 102, 174201 (2020).

[15] T. C. Nicholas, A. L. Goodwin, and V. L. Deringer, Understanding the geometric diversity of inorganic and hybrid frameworks through structural coarse-graining, Chem. Sci. 11, 12580 (2020).

[16] V. L. Deringer, M. A. Caro, and G. Csányi, A general-purpose machine-learning force field for bulk and nanostructured phosphorus, Nature Commun. 11, 5461 (2020).

[17] D. Dragoni, T. D. Daff, G. Csányi, and N. Marzari, Achieving DFT accuracy with a machine-learning interatomic potential: Thermomechanics and defects in bcc ferromagnetic iron, Phys. Rev. Mat. 2, 013808 (2018).

[18] L. Zhang, D.-Y. Lin, H. Wang, R. Car, and E. Weinan, Active learning of uniformly accurate interatomic potentials for materials simulation, Phys. Rev. Mat. 3, 023804 (2019).

[19] N. Bernstein, G. Csányi, and V. L. Deringer, De novo exploration and self-guided learning of potential-energy surfaces, npj Comput. Mat. 5, (2019).

[20] N. Artrith and J. Behler, High-dimensional neural network potentials for metal surfaces: A prototype study for copper, Phys. Rev. B 85, 045439 (2012).
[21] E. V. Podryabinkin and A. V. Shapeev, Active learning of linearly parametrized interatomic potentials, Comput. Mater. Sci. 140, 171 (2017).

[22] R. Jinnouchi, F. Karsai, and G. Kresse, On-the-fly machine learning force field generation: Application to melting points, Phys. Rev. B 100, 014105 (2019).

[23] R. Jinnouchi, K. Miwa, F. Karsai, G. Kresse, and R. Asahi, On-the-fly active learning of interatomic potentials for large-scale atomistic simulations, J. Phys. Chem. Lett. 11, 6946 (2020).

[24] J. Vandermause, S. B. Torrisi, S. Batzner, Yu Xie, L. Sun, A. M. Kolpak, and B. Kozinsky, On-the-fly active learning of interpretable bayesian force fields for atomistic rare events, npj Comput. Mater. 6, 20 (2020).

[25] F. Maresca, D. Dragoni, G. Csányi, N. Marzari, and W. A Curtin, Screw dislocation structure and mobility in body centered cubic Fe predicted by a Gaussian Approximation Potential, npj Comput. Mater. 4, 69 (2018).

[26] G. Imbalzano, A. Anelli, D. Giofré, S. Klees, J. Behler, and M. Ceriotti, Automatic selection of atomic fingerprints and reference configurations for machine-learning potentials, J. Chem. Phys. 148, 241730 (2018).

[27] N. Lopanitsyna, C. Ben Mahmoud, and M. Ceriotti, Finitetemperature materials modeling from the quantum nuclei to the hot electron regime, Phys. Rev. Materials 5, 043802 (2021).

[28] P. Giannozzi, S. Baroni, N. Bonini, M. Calandra, R. Car, C. Cavazzoni, D. Ceresoli, G. L. Chiarotti, M. Cococcioni, I. Dabo, A. D. Corso, S. D. Gironcoli, S. Fabris, G. Fratesi, R. Gebauer, U. Gerstmann, C. Gougoussis, A. Kokalj, M. Lazzeri, L. Martin-Samos, N. Marzari, F. Mauri, R. Mazzarello, S. Paolini, A. Pasquarello, L. Paulatto, C. Sbraccia, S. Scandolo, G. Sclauzero, A. P. Seitsonen, A. Smogunov, P. Umari, and R. M. Wentzcovitch, QUANTUM ESPRESSO: A modular and open-source software project for quantum simulations of materials, J. Phys.: Condens. Matter 21, 395502 (2009).

[29] J. P. Perdew, K. Burke, and M. Ernzerhof, Generalized Gradient Approximation Made Simple, Phys. Rev. Lett. 77, 3865 (1996).

[30] J. D. Pack and H. J. Monkhorst, Special points for Brillouinzone integrations, Phys. Rev. B 16, 1748 (1977).

[31] G. Prandini, A. Marrazzo, I. E. Castelli, N. Mounet, and N. Marzari, Precision and efficiency in solid-state pseudopotential calculations, npj Comput. Mater. 4, 72 (2018).

[32] G. Pizzi, A. Cepellotti, R. Sabatini, N. Marzari, and B. Kozinsky, AiiDA: automated interactive infrastructure and database for computational science, Comput. Mater. Sci. 111 218 (2016)

[33] S. P. Huber, S. Zoupanos, M. Uhrin, L. Talirz, L. Kahle, R. Häuselmann, D. Gresch, T. Müller, A. V. Yakutovich, C. W. Andersen, F. F. Ramirez, C. S. Adorf, F. Gargiulo, S. Kumbhar, E. Passaro, C. Johnston, A. Merkys, A. Cepellotti, N. Mounet, N. Marzari, B. Kozinsky, and G. Pizzi, AiiDA 1.0, A scalable computational infrastructure for automated reproducible workflows and data provenance, Sci. Data 7, 300 (2020).

[34] D. Giofré, T. Junge, W. A. Curtin, and M. Ceriotti, Ab initio modeling of the early stages of precipitation in Al-6000 alloys, Acta Mater. 140, 240 (2017).

[35] A. Singraber, T. Morawietz, J. Behler, and C. Dellago, Parallel multistream training of high-dimensional neural network potentials, J. Chem. Theory Comput. 15, 3075 (2019). 
[36] A. Singraber, J. Behler, and C. Dellago, Library-based LAMMPS implementation of high-dimensional neural network potentials, J. Chem. Theory Comput. 15, 1827 (2019).

[37] S. Plimpton, Fast parallel algorithms for short-range molecular dynamics, J. Comp. Phys. 117, 1 (1995).

[38] Y. Zuo, C. Chen, X.-G. Li, Z. Deng, Y. Chen, J. Behler, G. Csányi, A. V. Shapeev, A. P. Thompson, M. A. Wood, and S. P. Ong, A performance and cost assessment of machine learning interatomic potentials, J. Phys. Chem. A (2020).

[39] Yi $\mathrm{Hu}$ and W. A. Curtin, Modeling peak-aged precipitate strengthening in Al-Mg-Si alloys, J. Mech. Phys. Solids 151, 104378 (2021).

[40] C. Cayron, Groupoid of orientational variants, Acta Cryst. Sec. A: Found. Crystallogr. 62, 21 (2006).

[41] C. Cayron, GenOVa: A computer program to generate orientational variants, J. Appl. Crystallogr. 40, 1179 (2007).

[42] B. Yin, Z. Wu, and W. A. Curtin, Comprehensive first-principles study of stable stacking faults in hcp metals, Acta Mater. 123, 223 (2017).

[43] A. Hjorth Larsen, J. Jørgen Mortensen, J. Blomqvist, I. E. Castelli, R. Christensen, M. Dułak, J. Friis, M. N. Groves, B. Hammer, C. Hargus, E. D. Hermes, P. C. Jennings, P. Bjerre Jensen, J. Kermode, J. R. Kitchin, E. Leonhard Kolsbjerg, J. Kubal, K. Kaasbjerg, S. Lysgaard, J. Bergmann Maronsson, T. Maxson, T. Olsen, L. Pastewka, A. Peterson, C. Rostgaard, J. Schiøtz, O. Schütt, M. Strange, K. S. Thygesen, T. Vegge, L. Vilhelmsen, M. Walter, Z. Zeng, and K. W. Jacobsen, The atomic simulation environment - A Python library for working with atoms, J. Phys. Condens. Matter 29, 273002 (2017).

[44] A. Togo and I. Tanaka, Spglib: A software library for crystal symmetry search, pp. 1-11, 2018.

[45] V. Kapil, M. Rossi, O. Marsalek, R. Petraglia, Y. Litman, T. Spura, B. Cheng, A. Cuzzocrea, R. H. Meiner, D. M. Wilkins et al., i-PI 2.0: A universal force engine for advanced molecular simulations, Comput. Phys. Commun. 236, 214 (2019).
[46] S. Pogatscher, H. Antrekowitsch, M. Werinos, F. Moszner, S. S. A. Gerstl, M. F. Francis, W. A. Curtin, J. F. Löffler, and P. J. Uggowitzer, Diffusion on Demand to Control Precipitation Aging: Application to Al-Mg-Si Alloys, Phys. Rev. Lett. 112, 225701 (2014).

[47] M. Mantina, Y. Wang, L. Q. Chen, Z. K. Liu, and C. Wolverton, First principles impurity diffusion coefficients, Acta Mater. 57, 4102 (2009).

[48] M. Mantina, Y. Wang, R. Arroyave, L. Chen, Z. Liu, and C. Wolverton, First-Principles Calculation of Self-Diffusion Coefficients, Phys. Rev. Lett. 100, 215901 (2008).

[49] P. Dumitraschkewitz, P. J. Uggowitzer, S. S. A. Gerstl, J. F. Löffler, and S. Pogatscher, Size-dependent diffusion controls natural aging in aluminium alloys, Nature Commun. 10, 4746 (2019).

[50] S. Pogatscher, H. Antrekowitsch, H. Leitner, T. Ebner, and P. J. Uggowitzer, Mechanisms controlling the artificial aging of AlMg-Si alloys, Acta Materialia, 59, 3352 (2011).

[51] L. Talirz, S. Kumbhar, E. Passaro, A. V. Yakutovich, V. Granata, F. Gargiulo, M. Borelli, M. Uhrin, S. P. Huber, S. Zoupanos, C. S. Adorf, C. W. Andersen, O. Schütt, C. A. Pignedoli, D. Passerone, J. VandeVondele, T. C. Schulthess, B. Smit, G. Pizzi, and N. Marzari, Materials cloud, a platform for open computational science, Scientific Data 7, 299 (2020).

[52] D. Marchand, A. Jain, A. Glensk, and W. A. Curtin, Machine learning for metallurgy: A neural network potential for Al-Cu, Materials Cloud Archive 2020, 119 (2020).

[53] A. C. P. Jain, D. Marchand, A. Glensk, M. Ceriotti, and W. A. Curtin, Machine learning for metallurgy: A neural network potential for Al-Mg-Si, Materials Cloud Archive 2020, 32 (2020).

[54] R. Ramakrishnan, P. O. Dral, M. Rupp, and O. A. Von Lilienfeld, Big data meets quantum chemistry approximations: The $\Delta$-machine learning approach, J. Chem. Theory Comput. 11, 2087 (2015). 